Cochrane Database of Systematic Reviews

\title{
Drugs for discoid lupus erythematosus (Review)
}

Jessop S, Whitelaw DA, Grainge MJ, Jayasekera P

Jessop S, Whitelaw DA, Grainge MJ, Jayasekera P.

Drugs for discoid lupus erythematosus.

Cochrane Database of Systematic Reviews 2017, Issue 5. Art. No.: CD002954.

DOI: 10.1002/14651858.CD002954.pub3.

www.cochranelibrary.com 
TABLE OF CONTENTS

HEADER 1

ABSTRACT

PLAIN LANGUAGE SUMMARY

SUMMARY OF FINDINGS

BACKGROUND

OBJECTIVES

METHODS

RESULTS

Figure 1.

Figure 2.

DISCUSSION

AUTHORS' CONCLUSIONS

ACKNOWLEDGEMENTS

REFERENCES

CHARACTERISTICS OF STUDIES

DATA AND ANALYSES

Analysis 1.1. Comparison 1 Fluocinonide versus hydrocortisone cream, Outcome 1 Resolution of skin lesions.

Analysis 2.1. Comparison 2 Acitretin versus hydroxychloroquine, Outcome 1 Resolution of skin lesions.

Analysis 2.2. Comparison 2 Acitretin versus hydroxychloroquine, Outcome 2 Clearing of erythema. APPENDICES

WHAT'S NEW

HISTORY

CONTRIBUTIONS OF AUTHORS

DECLARATIONS OF INTEREST

SOURCES OF SUPPORT

DIFFERENCES BETWEEN PROTOCOL AND REVIEW

INDEX TERMS 
[Intervention Review]

\section{Drugs for discoid lupus erythematosus}

Sue Jessop ${ }^{1}$, David A Whitelaw², Matthew J Grainge³ ${ }^{3}$ Prativa Jayasekera4

1Department of Medicine, University of Cape Town Groote Schuur Hospital, Cape Town, South Africa. 2Department of Medicine, Division of Rheumatology, University of Stellenbosch, Cape Town, South Africa. ${ }^{3}$ Division of Epidemiology and Public Health, School of Medicine, Nottingham, UK. ${ }^{4}$ Department of Dermatology, Broadgreen Hospital, Liverpool, UK

Contact address: Sue Jessop, Department of Medicine, University of Cape Town Groote Schuur Hospital, Main Road, 7925 Observatory Cape Town, Cape Town, Western Cape, South Africa.susan.jessop@uct.ac.za, davesue@mweb.co.za.

Editorial group: Cochrane Skin Group.

Publication status and date: New search for studies and content updated (no change to conclusions), published in Issue 5, 2017.

Citation: Jessop S, Whitelaw DA, Grainge MJ, Jayasekera P. Drugs for discoid lupus erythematosus. Cochrane Database of Systematic Reviews 2017, Issue 5. Art. No.: CD002954. DOI: 10.1002/14651858.CD002954.pub3.

Copyright @ 2017 The Cochrane Collaboration. Published by John Wiley \& Sons, Ltd.

\section{A B S T R A C T}

\section{Background}

Discoid lupus erythematosus (DLE) is a chronic form of cutaneous lupus, which can cause scarring. Many drugs have been used to treat this disease and some (such as thalidomide, cyclophosphamide and azathioprine) are potentially toxic. This is an update of a Cochrane Review first published in 2000, and previously updated in 2009. We wanted to update the review to assess whether any new information was available to treat DLE, as we were still unsure of the effectiveness of available drugs and how to select the most appropriate treatment for an individual with DLE.

\section{Objectives}

To assess the effects of drugs for discoid lupus erythematosus.

\section{Search methods}

We updated our searches of the following databases to 22 September 2016: the Cochrane Skin Specialised Register, CENTRAL, MEDLINE, Embase and LILACS. We also searched five trials databases, and checked the reference lists of included studies for further references to relevant trials. Index Medicus (1956 to 1966) was handsearched and we approached authors for information about unpublished trials.

\section{Selection criteria}

We included all randomised controlled trials (RCTs) of drugs to treat people with DLE in any population group and of either gender. Comparisons included any drug used for DLE against either another drug or against placebo cream. We excluded laser treatment, surgery, phototherapy, other forms of physical therapy, and photoprotection as we did not consider them drug treatments.

\section{Data collection and analysis}

At least two reviewers independently extracted data onto a data extraction sheet, resolving disagreements by discussion. We used standard methods to assess risk of bias, as expected by Cochrane.

\section{Main results}

Five trials involving 197 participants were included. Three new trials were included in this update. None of the five trials were of high quality.

'Risk of bias' assessments identified potential sources of bias in each study. One study used an inappropriate randomisation method, and incomplete outcome data were a concern in another as 15 people did not complete the trial. We found most of the trials to be at low risk in terms of blinding, but three of the five did not describe allocation concealment. 
The included trials inadequately addressed the primary outcome measures of this review (percentage with complete resolution of skin lesions, percentage with clearing of erythema in at least $50 \%$ of lesions, and improvement in patient satisfaction/quality of life measures).

One study of fluocinonide cream $0.05 \%$ (potent steroid) compared with hydrocortisone cream $1 \%$ (low-potency steroid) in 78 people reported complete resolution of skin lesions in $27 \%$ (10/37) of participants in the fluocinonide cream group and in $10 \%$ (4/41) in the hydrocortisone group, giving a $17 \%$ absolute benefit in favour of fluocinonide (risk ratio (RR) $2.77,95 \% \mathrm{Cl} 0.95$ to $8.08,1$ study, $\mathrm{n}=78$, low-quality evidence). The other primary outcome measures were not reported. Adverse events did not require discontinuation of the drug. Skin irritation occurred in three people using hydrocortisone, and one person developed acne. Burning occurred in two people using fluocinonide (moderate-quality evidence).

A comparative trial of two oral agents, acitretin ( $50 \mathrm{mg}$ daily) and hydroxychloroquine ( $400 \mathrm{mg}$ daily), reported two of the outcomes of interest: complete resolution was seen in 13 of 28 participants (46\%) on acitretin and 15 of 30 participants (50\%) on hydoxychloroquine (RR $0.93,95 \% \mathrm{Cl} 0.54$ to $1.59,1$ study, $\mathrm{n}=58$, low-quality evidence). Clearing of erythema in at least $50 \%$ of lesions was reported in 10 of 24 participants (42\%) on acitretin and 17 of $25(68 \%)$ on hydroxychloroquine (RR $0.61,95 \% \mathrm{Cl} 0.36$ to $1.06,1$ study, $\mathrm{n}=49$, lowquality evidence). This comparison did not assess improvement in patient satisfaction/quality of life measures. Participants taking acitretin showed a small increase in serum triglyceride, not sufficient to require withdrawal of the drug. The main adverse effects were dry lips (93\% of the acitretin group and $20 \%$ of the hydroxychloroquine group) and gastrointestinal disturbance (11\% of the acitretin group and $17 \%$ of the hydroxychloroquine group). Four participants on acitretin withdrew due to gastrointestinal events or dry lips (moderate-quality evidence).

One trial randomised 10 people with DLE to apply a calcineurin inhibitor, pimecrolimus $1 \%$ cream, or a potent steroid, betamethasone 17 valerate $0.1 \%$ cream, for eight weeks. The study reported none of the primary outcome measures, nor did it present data on adverse events.

A trial of calcineurin inhibitors compared tacrolimus cream $0.1 \%$ with placebo (vehicle) over 12 weeks in 14 people, but reported none of our primary outcome measures. In the tacrolimus group, five participants complained of slight burning and itching, and for one participant, a herpes simplex infection was reactivated (moderate-quality evidence).

Topical R-salbutamol $0.5 \%$ cream was compared with placebo (vehicle) over eight weeks in one trial of 37 people with DLE. There was a significant improvement in pain and itch in the salbutamol group at two, four, six, and eight weeks compared to placebo, but the trial did not record a formal measure of quality of life. None of the primary outcome measures were reported. Changes in erythema did not show benefit of salbutamol over placebo, but we could not obtain from the trial report the number of participants with clearing of erythema in at least $50 \%$ of lesions. There were 15 events in the placebo group (experienced by 12 participants) and 24 in the salbutamol group (experienced by nine participants). None of the adverse events were considered serious (moderate-quality evidence).

\section{Authors' conclusions}

Fluocinonide cream may be more effective than hydrocortisone in clearing DLE skin lesions. Hydroxychloroquine and acitretin appear to be of equal efficacy in terms of complete resolution, although adverse effects might be more frequent with acitretin, and clearing of erythema in at least $50 \%$ of lesions occurred less often in participants applying acitretin. Moderate-quality evidence found adverse events were minor on the whole. There is not enough reliable evidence about other drugs used to treat DLE. Overall, the quality of the trials and levels of uncertainty were such that there is a need for further trials of sufficient duration comparing, in particular, topical steroids with other agents.

\section{PLAIN LANGUAGE SUMMARY}

\section{Drugs for discoid lupus erythematosus}

\section{Background}

Discoid lupus erythematosus (DLE) is a form of skin inflammation which occurs particularly on sun-exposed skin and can cause scarring. All forms of cutaneous lupus erythematosus are most common in women of childbearing age, which is important because some treatments, including thalidomide and acitretin, can cause birth defects, and hydroxychloroquine may cause damage to the eye or ear. As the chronic nature and scarring of DLE can have psychological impact, and some treatments may produce serious adverse effects, we felt it was important to combat uncertainty and identify the best and safest treatment. The evidence is current to September 2016.

\section{Review question}

We aimed to identify the best treatment for people with DLE, to reduce the risk of scarring and possible psychological effects. We searched for all possible drug treatments, including topical agents (steroids and pimecrolimus or tacrolimus) and oral agents, such as hydroxychloroquine, retinoids, methotrexate, azathioprine, lenalidomide, and biological agents. Potentially, any of these interventions could have been compared with placebo or with any other intervention. We excluded surgery, laser, photoprotection, phototherapy, and other forms of physical therapy as we did not consider them drug treatments. We hoped to find evidence for effective treatment, without serious adverse effects.

\section{Study characteristics}


We identified five studies, involving 197 people (aged between 17 and 82). Participants were recruited from Europe, Scandinavia, Iran, and the United States. Most of the skin lesions were recorded on the face, ear, and scalp. The duration of disease ranged from one month to 16 years. Treatments included steroid creams of different potencies (fluocinonide and betamethasone cream, both potent steroids; and hydrocortisone, a low-potency steroid); oral hydroxychloroquine; oral acitretin; tacrolimus cream; pimecrolimus cream; and salbutamol cream. The tacrolimus and salbutamol trials used placebo in the control arm.

\section{Key results}

In a trial involving 78 participants, fluocinonide cream $0.05 \%$ appeared nearly three times as effective as hydrocortisone cream $1 \%$ in terms of complete clearing of the DLE (27\% versus $10 \%)$. The percentage of people who had a reduction in the redness of at least $50 \%$ of their sores was not reported, nor was patient satisfaction. Skin irritation occurred in three people using hydrocortisone and one person developed acne; burning occurred in two people using fluocinonide. Adverse events did not stop any participants continuing to apply the creams.

Hydroxychloroquine $400 \mathrm{mg}$ and acitretin $50 \mathrm{mg}$ appear to work equally well in terms of complete resolution (50\% versus $46 \%$, respectively). Marked improvement in redness may be less in the acitretin group (42\% versus $68 \%$ ), but neither drug has been compared with placebo. Patient satisfaction was not measured. Adverse events, more common in the acitretin group, were reported as minor, although four people stopped treatment due to dry lips and gastrointestinal symptoms.

Pimecrolimus cream $1 \%$ (an anti-inflammatory cream) was compared with betamethasone (steroid) $0.1 \%$ cream in a small 8 -week study involving 10 people, but none of the review primary outcomes were reported; nor were adverse effects.

A longer study using a similar type of cream, tacrolimus $0.1 \%$, compared with placebo did not report the primary outcomes. Slight burning and itching was reported in five participants applying tacrolimus, and a herpes simplex infection came back in one participant. A few people reported burning or irritation after the use of tacrolimus cream, but not sufficient to cause withdrawal.

R-salbutamol $0.5 \%$ topical cream was compared with placebo cream in a trial of 37 people, but the primary outcomes of this review were not reported. There were only minor adverse events reported in each group: 15 in the placebo group and 24 in the salbutamol group.

\section{Quality of the evidence}

For our primary outcome of clearing or excellent improvement, we had low-quality evidence for fluocinonide $0.05 \%$ compared with hydrocortisone $1 \%$ as the only study assessing this comparison contained a high number of dropouts; while for acitretin ( $50 \mathrm{mg}$ ) compared with hydroxychloroquine $(400 \mathrm{mg})$, for our primary outcomes of reduction in erythema and complete resolution we rated the quality of evidence as low, as the study contained a small number of people and differences between the groups in the number of people who had forms of lupus other than DLE. Overall, moderate-quality evidence was found for adverse events. 
SUMMARY OF FINDINGS

Summary of findings for the main comparison. Fluocinonide $\mathbf{0 . 0 5} \%$ compared with hydrocortisone $1 \%$

Fluocinonide $\mathbf{0 . 0 5} \%$ compared with hydrocortisone $1 \%$ for discoid lupus erythematosus

Patient or population: people with discoid lupus erythematosus

\section{Settings: not stated}

Intervention: fluocinonide

Comparison: hydrocortisone

\begin{tabular}{|c|c|c|c|c|c|c|}
\hline \multirow[t]{3}{*}{ Outcomes } & \multicolumn{2}{|c|}{$\begin{array}{l}\text { Illustrative comparative risks }{ }^{\star} \\
(95 \% \mathrm{CI})\end{array}$} & \multirow[t]{3}{*}{$\begin{array}{l}\text { Relative effect } \\
(95 \% \mathrm{CI})\end{array}$} & \multirow{3}{*}{$\begin{array}{l}\text { No of Partici- } \\
\text { pants } \\
\text { (studies) }\end{array}$} & \multirow{3}{*}{$\begin{array}{l}\text { Quality of the } \\
\text { evidence } \\
\text { (GRADE) }\end{array}$} & \multirow[t]{3}{*}{ Comments } \\
\hline & Assumed risk & $\begin{array}{l}\text { Corresponding } \\
\text { risk }\end{array}$ & & & & \\
\hline & $\begin{array}{l}\text { hydrocorti- } \\
\text { sone }\end{array}$ & fluocinonide & & & & \\
\hline $\begin{array}{l}\text { At least } 50 \% \text { reduction in } \\
\text { erythema }\end{array}$ & see comment & see comment & see comment & see comment & see comment & This outcome was not assessed. \\
\hline Quality of life measure & see comment & see comment & see comment & see comment & see comment & This outcome was not assessed. \\
\hline Relapse & see comment & see comment & see comment & see comment & see comment & This outcome was not assessed. \\
\hline $\begin{array}{l}\text { Adverse events of medica- } \\
\text { tion, leading to discontin- } \\
\text { uation or significant mor- } \\
\text { bidity }\end{array}$ & see comment & see comment & see comment & $\begin{array}{l}78 \\
\text { (1 study) }\end{array}$ & Moderate $^{2}$ & $\begin{array}{l}\text { The number of adverse events in this study } \\
\text { was small and results were presented nar- } \\
\text { ratively. For hydrocortisone, } 1 \text { person devel- } \\
\text { oped acne and } 3 \text { experienced irritation. } 2 \text { pa- } \\
\text { tients who were assigned to fluocinonide ex- } \\
\text { perienced burning. There was no discontinu- } \\
\text { ation in either group. }\end{array}$ \\
\hline
\end{tabular}


*The basis for the assumed risk (e.g. the median control group risk across studies) is provided in footnotes. The corresponding risk (and its $95 \%$ confidence interval) is based on the assumed risk in the comparison group and the relative effect of the intervention (and its $95 \% \mathrm{Cl}$ ).

Cl: Confidence interval; RR: Risk Ratio

GRADE Working Group grades of evidence

High quality: Further research is very unlikely to change our confidence in the estimate of effect.

Moderate quality: Further research is likely to have an important impact on our confidence in the estimate of effect and may change the estimate.

Low quality: Further research is very likely to have an important impact on our confidence in the estimate of effect and is likely to change the estimate.

Very low quality: We are very uncertain about the estimate.

The assumed risk was the mean risk for the study population

1Downgraded by two levels due to imprecision and high risk of bias (incomplete outcome data).

2Downgraded by one level for imprecision (small sample size).

\section{Summary of findings 2. Acitretin $\mathbf{5 0} \mathbf{~ m g}$ daily compared with hydroxychloroquine $\mathbf{4 0 0} \mathbf{~ m g}$ daily}

Acitretin $\mathbf{5 0} \mathrm{mg}$ daily compared with hydroxychloroquine $\mathbf{4 0 0} \mathbf{~ m g}$ daily for discoid lupus erythematosus

Patients or population: people with discoid lupus erythematosus

Settings: specialised lupus clinic

Intervention: acitretin

Comparison: hydroxychloroquine

\begin{tabular}{|c|c|c|c|c|c|c|}
\hline \multirow[t]{3}{*}{ Outcomes } & \multicolumn{2}{|c|}{$\begin{array}{l}\text { Illustrative comparative risks* } \\
(95 \% \mathrm{CI})\end{array}$} & \multirow[t]{3}{*}{$\begin{array}{l}\text { Relative effect } \\
(95 \% \mathrm{Cl})\end{array}$} & \multirow{3}{*}{$\begin{array}{l}\text { No of Partici- } \\
\text { pants } \\
\text { (studies) }\end{array}$} & \multirow{3}{*}{$\begin{array}{l}\text { Quality of the } \\
\text { evidence } \\
\text { (GRADE) }\end{array}$} & \multirow[t]{3}{*}{ Comments } \\
\hline & Assumed risk & $\begin{array}{l}\text { Corresponding } \\
\text { risk }\end{array}$ & & & & \\
\hline & $\begin{array}{l}\text { hydroxy- } \\
\text { chloroquine }\end{array}$ & acitretin & & & & \\
\hline $\begin{array}{l}\text { At least } 50 \% \text { reduction in } \\
\text { erythema }\end{array}$ & 68 per 100 & $\begin{array}{l}42 \text { per } 100 \\
\text { ( } 25 \text { to } 72 \text { ) }\end{array}$ & $\begin{array}{l}0.61(0.36 \text { to } \\
1.06)\end{array}$ & $\begin{array}{l}49 \\
\text { (1 study) }\end{array}$ & Low $^{1}$ & - \\
\hline
\end{tabular}


(after 8 weeks of treatment)

\begin{tabular}{|c|c|c|c|c|c|c|}
\hline Quality of life measure & see comment & see comment & see comment & see comment & see comment & This outcome was not assessed. \\
\hline Relapse & see comment & see comment & see comment & see comment & see comment & This outcome was not assessed. \\
\hline
\end{tabular}

*The basis for the assumed risk (e.g. the median control group risk across studies) is provided in footnotes. The corresponding risk (and its $95 \%$ confidence interval) is based on the assumed risk in the comparison group and the relative effect of the intervention (and its $95 \% \mathrm{Cl}$ ).

Cl: Confidence interval; RR: Risk Ratio

GRADE Working Group grades of evidence

High quality: Further research is very unlikely to change our confidence in the estimate of effect.

Moderate quality: Further research is likely to have an important impact on our confidence in the estimate of effect and may change the estimate.

Low quality: Further research is very likely to have an important impact on our confidence in the estimate of effect and is likely to change the estimate.

Very low quality: We are very uncertain about the estimate.

The assumed risk was the mean risk for the study population.

1Downgraded by two levels due to imprecision and high risk of bias (non-comparable treatment arms).

2Downgraded by one level for imprecision (small sample size).

\section{Summary of findings 3 . Pimecrolimus $1 \%$ compared with betamethasone 17 -valerate $0.1 \%$}

Pimecrolimus $1 \%$ compared with betamethasone 17 -valerate $0.1 \%$ for discoid lupus erythematosus

Patients or population: people with discoid lupus erythematosus

Settings: dermatology clinics

Intervention: pimecrolimus

Comparison: betamethasone

\begin{tabular}{|c|c|c|c|c|c|}
\hline Outcomes & $\begin{array}{l}\text { Illustrative com- } \\
\text { parative risks* } \\
(95 \% \mathrm{Cl})\end{array}$ & $\begin{array}{l}\text { Relative effect } \\
(95 \% \mathrm{CI})\end{array}$ & $\begin{array}{l}\text { No of Participants } \\
\text { (studies) }\end{array}$ & $\begin{array}{l}\text { Quality of the evi- } \\
\text { dence } \\
\text { (GRADE) }\end{array}$ & Comments \\
\hline
\end{tabular}




\begin{tabular}{|c|c|c|c|c|c|c|}
\hline 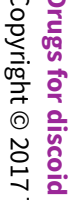 & $\begin{array}{l}\text { Clearing or excellent improve- } \\
\text { ment } \\
\text { (after } 8 \text { weeks of treatment) }\end{array}$ & see comment & see comment & 10 & see comment & $\begin{array}{l}\text { There was a statistically significant reduction } \\
\text { in the disease severity score in both treat- } \\
\text { ment groups; however, clearing or improve- } \\
\text { ment was not presented as a percentage and } \\
\text { no comparative analyses were performed. }\end{array}$ \\
\hline 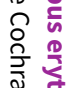 & $\begin{array}{l}\text { At least } 50 \% \text { reduction in ery- } \\
\text { thema }\end{array}$ & see comment & see comment & see comment & see comment & This outcome was not assessed. \\
\hline$\stackrel{乛}{0}$ & Quality of life measure & see comment & see comment & see comment & see comment & This outcome was not assessed. \\
\hline & Relapse & see comment & see comment & see comment & see comment & This outcome was not assessed. \\
\hline 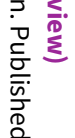 & $\begin{array}{l}\text { Adverse events of medication, } \\
\text { leading to discontinuation or } \\
\text { significant morbidity }\end{array}$ & see comment & see comment & see comment & see comment & This outcome was not assessed. \\
\hline & \multicolumn{6}{|c|}{$\begin{array}{l}\text { *The basis for the assumed risk (e.g. the median control group risk across studies) is provided in footnotes. The corresponding risk (and its } 95 \% \text { confidence interval) is } \\
\text { based on the assumed risk in the comparison group and the relative effect of the intervention (and its } 95 \% \mathrm{Cl} \text { ). } \\
\text { CI: Confidence interval; RR: Risk Ratio }\end{array}$} \\
\hline
\end{tabular}

GRADE Working Group grades of evidence

High quality: Further research is very unlikely to change our confidence in the estimate of effect.

Moderate quality: Further research is likely to have an important impact on our confidence in the estimate of effect and may change the estimate.

Low quality: Further research is very likely to have an important impact on our confidence in the estimate of effect and is likely to change the estimate.

Very low quality: We are very uncertain about the estimate.

\section{Summary of findings 4 . R-salbutamol $0.5 \%$ topical cream compared with placebo}

R-salbutamol 0.5\% topical cream compared with placebo for discoid lupus erythematosus

Patient or population: people with discoid lupus erythematosus

Settings: dermatology departments

Intervention: R-salbutamol

Comparison: placebo

\begin{tabular}{lllll}
\hline Outcomes & $\begin{array}{l}\text { Illustrative com- } \\
\text { parative risks } \\
(95 \% \mathrm{Cl})\end{array}$ & $\begin{array}{l}\text { Relative effect } \\
(95 \% \mathrm{Cl})\end{array}$ & $\begin{array}{l}\text { No of Participants } \\
\text { (studies) }\end{array}$ & $\begin{array}{l}\text { Quality of the evi- } \\
\text { dence } \\
\text { (GRADE) }\end{array}$ \\
\hline
\end{tabular}

$\checkmark$

(95\% CI) 


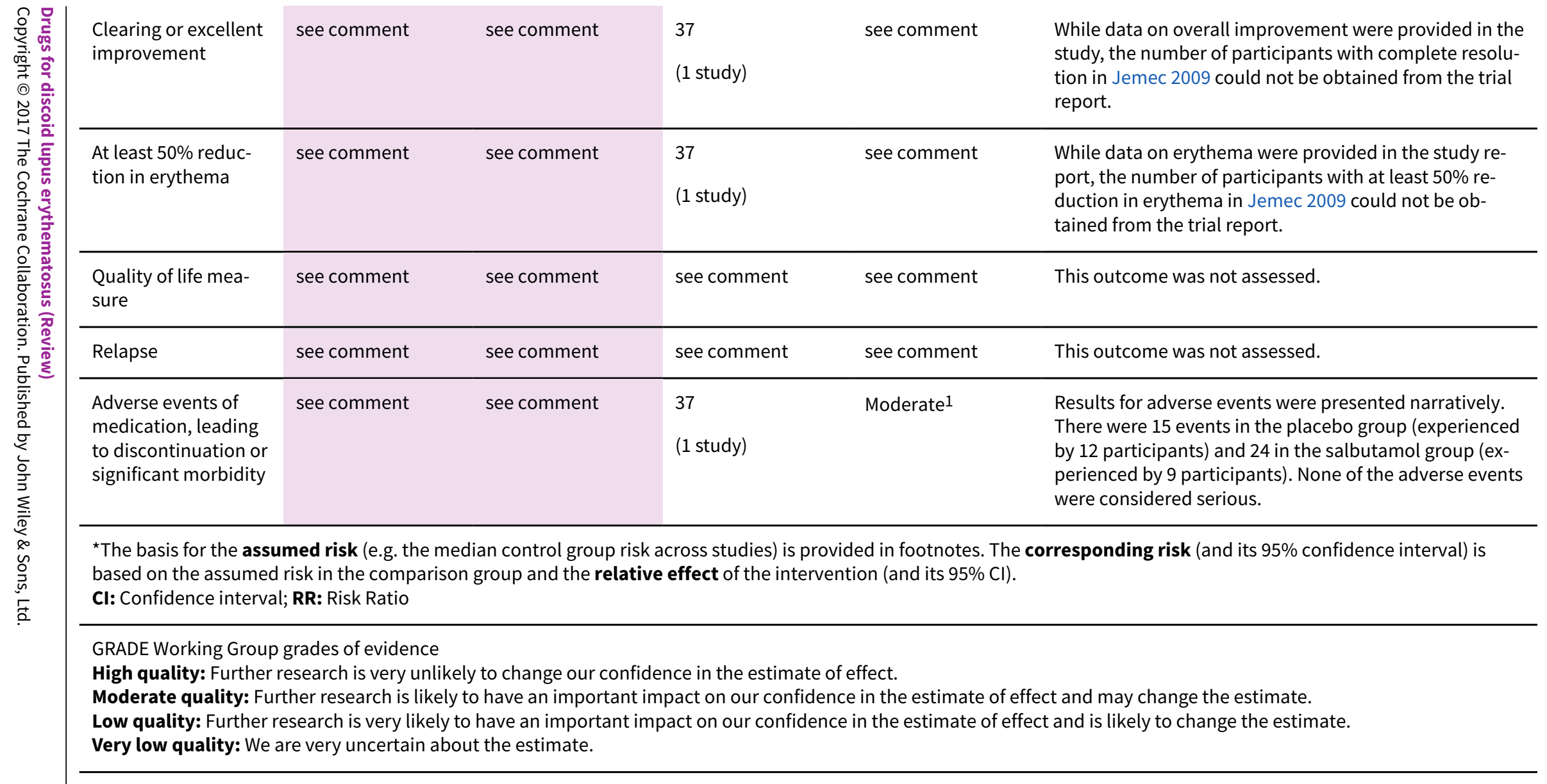

1Downgraded by one level for imprecision (small sample size).

\section{Summary of findings 5 . Tacrolimus $0.1 \%$ cream compared with placebo}

\section{Tacrolimus $0.1 \%$ cream compared with placebo for discoid lupus erythematosus}

Patient or population: people with discoid lupus erythematosus

Settings: dermatology departments

Intervention: tacrolimus 


\begin{tabular}{|c|c|c|c|c|c|}
\hline Outcomes & $\begin{array}{l}\text { Illustrative com- } \\
\text { parative risks } \\
(95 \% \mathrm{CI})\end{array}$ & $\begin{array}{l}\text { Illustrative com- } \\
\text { parative risks } \\
(95 \% \mathrm{CI})\end{array}$ & $\begin{array}{l}\text { No of Participants } \\
\text { (studies) }\end{array}$ & $\begin{array}{l}\text { Quality of the evi- } \\
\text { dence } \\
\text { (GRADE) }\end{array}$ & Comments \\
\hline $\begin{array}{l}\text { Clearing or excellent } \\
\text { improvement }\end{array}$ & see comment & see comment & see comment & see comment & $\begin{array}{l}\text { No participants with DLE in either group in the study } \\
\text { by Kuhn } 2011 \text { experienced complete clearing. Unable } \\
\text { to GRADE due to } 0 \text { events in both groups. }\end{array}$ \\
\hline $\begin{array}{l}\text { At least } 50 \% \text { reduction } \\
\text { in erythema }\end{array}$ & see comment & see comment & see comment & see comment & $\begin{array}{l}\text { The results for erythema in the study by Kuhn } 2011 \\
\text { were not reported separately. }\end{array}$ \\
\hline Quality of life measure & see comment & see comment & see comment & see comment & This outcome was not measured. \\
\hline Relapse & see comment & see comment & see comment & see comment & This outcome was not measured. \\
\hline $\begin{array}{l}\text { Adverse events of } \\
\text { medication, leading to } \\
\text { discontinuation or sig- } \\
\text { nificant morbidity }\end{array}$ & see comment & see comment & $\begin{array}{l}14 \\
\text { (1 study) }\end{array}$ & Moderate ${ }^{1}$ & $\begin{array}{l}\text { Results for adverse events were presented narrative- } \\
\text { ly. In the tacrolimus group, } 5 \text { participants complained } \\
\text { of slight burning and itching, and in } 1 \text { person a herpes } \\
\text { simplex infection was reactivated. There were no seri- } \\
\text { ous adverse events. }\end{array}$ \\
\hline
\end{tabular}

GRADE Working Group grades of evidence

High quality: Further research is very unlikely to change our confidence in the estimate of effect.

Moderate quality: Further research is likely to have an important impact on our confidence in the estimate of effect and may change the estimate.

Low quality: Further research is very likely to have an important impact on our confidence in the estimate of effect and is likely to change the estimate.

Very low quality: We are very uncertain about the estimate.

1Downgraded by one level for imprecision (small sample size). 


\section{B A C K G R O U N D}

\section{Description of the condition}

Discoid lupus erythematosus (DLE) is a chronic and common form of cutaneous lupus - a form of skin inflammation of unknown cause. It occurs particularly on sun-exposed skin, such as the face, ears, and scalp, but occasionally is much more extensive, involving large areas of skin. Some people with DLE have associated disease in other parts of the body, but the majority of people with DLE are otherwise healthy. People with DLE are seen frequently in skin clinics throughout the world.

There have been no accurate studies of the prevalence of DLE, although all forms of lupus erythematosus are particularly common in women of childbearing age. The diagnosis of DLE is usually made easily on clinical grounds, characteristic clinical findings being erythema (redness), follicular plugging (blocked and enlarged openings to hair follicles), pigmentary disturbances, telangiectasia (dilated capillaries), and atrophy (skin thinning). When the diagnosis is in doubt, a skin biopsy (microscopic examination) may be required to confirm the diagnosis (Kuhn 2014).

In an attempt to improve consistency in the reporting of clinical trials, the CLASI (Cutaneous Lupus Erythematosus Area and Severity Index) scoring system has been developed (Albrecht 2005). The CLASI allows assessment of both active inflammation (erythema, scale, and hypertrophy) and damage (dyspigmentation, scarring, atrophy), in different body areas, but does not include a quality of life score. It has not been tested in different populations.

Early effective treatment may lead to total clearing of the skin lesions, but failure of treatment results in permanent scarring. The depressed scars, hair loss, and pigmentary changes are often extremely disfiguring, particularly in darker-skinned people. Permanent scarring is the rule if treatment is delayed or inadequate. Great emotional distress, social isolation, and difficulty obtaining work are problems frequently suffered by these patients. Involvement of the skin of the fingers and toes may markedly impair hand function and limit walking (Vasquez 2013). In addition, people with DLE are at risk of developing squamous cell carcinoma in the scarred areas (Fernandes 2015).

\section{Description of the intervention}

The anti-malarial drug chloroquine is the traditional therapy for DLE (Goldman 1953; Brodthagen 1959; Callen 1982). It is cheap and readily available worldwide. Flare-ups of systemic lupus were noted to occur with increased frequency after chloroquine was stopped (Rothfield 1963). However, some people cannot tolerate the drug and it is known to fail in others. Other anti-malarial agents have been used, sometimes in combination with chloroquine, but are not widely available (Kierland 1953; Maguire 1962; Feldman 1994).

In recent years, hydroxychloroquine has been used in place of chloroquine in many countries, because ocular side-effects were reported to be less frequent with hydroxychloroquine, but retinal toxicity has subsequently also been recognised with hydroxychloroquine (Geamanu 2014). The efficacy of the two forms of the drug is thought to be the same, but no trials exist to confirm this in DLE (Kreuter 2009). In discussing the treatment of DLE in 1961, Prakken commented that: "This [lack of evidence] is illustrated by a survey of our literature on the treatment of chronic lupus erythematosus. Although many papers agree on their reports of favourable results, the value of our therapy remains doubtful because the influence of the placebo effect and the publications effect has not been eliminated" (Prakken 1961). However, Rees felt that discoid lupus responded so dramatically to chloroquine that "double-blind studies are not required" (Rees 1963). In 1964, Kraak performed a literature search and concluded that available information was insufficient to evaluate the many therapies that are recommended: "The literature leaves room for the alarming assumption that none of the drugs might do any good" (Kraak 1964). His group performed a non-randomised double-blind trial comparing hydroxychloroquine with placebo (Kraak 1965). Spontaneous improvement or clearing occurred in some of their patients, particularly in the winter months (Kraak 1965). The group on chloroquine showed a greater tendency to improve (Kraak 1965). Other workers have been so concerned about possible ocular side-effects (thought to be very rare on current low dosage regimens) that chloroquine was excluded from their trial (Mackey 1974). Smoking may reduce the efficacy of chloroquine in people with lupus: a recent review reports studies that demonstrate an inverse relationship between number of cigarettes smoked and chloroquine blood levels (Chasset 2015). Unfortunately many of the other agents, reported anecdotally to be of value in discoid lupus erythematosus, have considerable potential side-effects and some, such as thalidomide, may produce major malformations in the foetus if taken during pregnancy (Cortés-Hernández 2012; Zhou 2013).

Many other agents have been used to treat this condition (Callen 1997). Sunscreens and sun avoidance reduce flares of cutaneous lupus, but are not usually sufficient alone (Kuhn 2011a). Other possible treatments include dapsone (Coburn 1982; Lindskov 1986), topical and intralesional steroids (please note that the term 'steroid' has been used in this review in place of the term 'corticosteroid', although both terms have the same meaning) (Jansen 1965; Marsden 1968; Reyman 1974; Smith 1986), gold (Dalziel 1986), clofazimine (Mackey 1974), retinoids (Ruzicka 1988; Shornick 1991), methotrexate (Goldstein 1994), azathioprine (Tsokos 1985), lenalidomide (Okon 2014), thalidomide (Hasper 1983; Knop 1983; Naafs 1985), topical salbutamol (Jemec 2009), sulphasalazine (Artuz 1996), phenytoin (Rodriguez-Castellanos 1995), interferon alpha-2a (Martinez 1992), topical calcineurin blockers (pimecrolimus and tacrolimus) (Wollina 2007; Tsellos 2008), and biological agents such as abatacept (Merrill 2010a), belimumab (Manzi 2012), efalizumab (Usmani 2007), etanercept, infliximab, rituximab, sifalimumab (Merrill 2011) and sirukumab (Szepietowski 2013)

\section{How the intervention might work}

Steroids have anti-inflammatory and immunosuppressive effects, acting on genetic material in the cell nucleus, via steroid receptors in the cell (Norris 2005). Tacrolimus and pimecrolimus, which are calcineurin inhibitors, inhibit the activity of $\mathrm{T}$ lymphocytes (via calcium channels), a key cell in the development of cutaneous lupus (Khandpur 2004). Salbutamol may exert an antiinflammatory effect by activating receptors on the surface of cells, particularly lymphocytes and eosinophils (Jemec 2009). Evidence suggests that chloroquine and hydroxychloroquine which are antimalarials, have an effect on inflammation by reducing antigen presentation and the production of inflammatory cytokines (Rainsford 2015). The anti-inflammatory mechanism of action of 
retinoids, such as acitretin, are not fully understood. Retinoid receptors allow access to the cell nucleus, and retinoids promote normal cell growth (Schroeder 2007).

\section{Why it is important to do this review}

Permanent scarring is likely if treatment is delayed or inadequate. People with DLE often experience great emotional distress. Social isolation and difficulty obtaining work are frequent problems. The relative efficacies of possible forms of treatment compared to placebo or each other need to be clearly established. Some of these agents (such as the cytotoxics) are potentially toxic (Weinblatt 2013; Goldberg 2015). Both thalidomide and the retinoids are highly teratogenic (they may cause birth defects when given to pregnant women), which renders their use in fertile women problematic (Ortiz 2013; Zhou 2013). It is this combination of uncertainty of relative effectiveness and some potential to cause considerable harm that has fuelled the need for this systematic review. This is an update of a Cochrane Review first published in 2000 (Jessop 2000); and previously updated in 2009 (Jessop 2009).

\section{OB JECTIVES}

To assess the effects of drugs for discoid lupus erythematosus.

\section{METHODS}

\section{Criteria for considering studies for this review}

\section{Types of studies}

Randomised controlled trials of drug therapy for discoid lupus erythematosus.

\section{Types of participants}

Participants at least 18 years of age.

A clinical diagnosis of discoid lupus erythematosus was accepted, with or without histological confirmation. Studies that enrolled people with different types of cutaneous lupus were included if the subgroup with DLE could be identified separately.

\section{Types of interventions}

Any drug treatment aimed at clearing or improving the lesions of DLE. This included:

- chloroquine, hydroxychloroquine, and other anti-malarial quinines;

- thalidomide and lenalidomide;

- steroids, topical and systemic;

- retinoids, including acitretin, etretinate, isotretinoin;

- azathioprine;

- methotrexate;

- dapsone;

- clofazimine;

- phenytoin;

- gold;

- sulphasalazine;

- interferon alpha-2a;
- biological agents, including abatacept, adalimumab, belimumab, etanercept, efalizumab, infliximab, rituximab, sifalimumab and sirukumab;

- topical calcineurin antagonists, including tacrolimus, pimecrolimus;

- topical salbutamol.

Potentially, any of these interventions could have been compared with placebo or with any other intervention. Delivery of the drug could be topical, parenteral or oral.

We excluded surgery, laser, photoprotection, phototherapy, and other forms of physical therapy as we did not consider them drug treatments.

\section{Types of outcome measures}

\section{Primary outcomes}

- Percentage of people with complete resolution of skin lesions (i.e. return to normal skin appearance).

- Percentage of people with clearing of erythema in at least $50 \%$ of lesions (post-inflammatory pigmentation could persist).

- Improvement in patient satisfaction/quality of life measures.

\section{Secondary outcomes}

- Relapse rate when medication stopped or reduced.

- Prevention of new lesions.

- Adverse effects of medication, leading to discontinuation or significant morbidity.

- Implications for health care costs.

\section{Search methods for identification of studies}

We aimed to identify all relevant RCTs regardless of language or publication status (published, unpublished, in press, or in progress).

\section{Electronic searches}

For this update, we revised the search strategies for CENTRAL, MEDLINE and Embase in line with current Cochrane Skin practices, and we re-ran our existing searches for the other databases. Details of the previous search strategies are available in Jessop 2000 and Jessop 2009.

We searched the following up to 22 September 2016.

- Cochrane Skin Specialised Register using the following terms: ((discoid and lupus) or (cutaneous and lupus)) and erythematosus.

- Cochrane Central Register of Controlled Trials (CENTRAL; 2016, Issue 8 ) in the Cochrane Library using the search strategy in Appendix 2.

- MEDLINE Ovid (from 1946) using the strategy in Appendix 3.

- Embase Ovid (from 1974) using the strategy in Appendix 4.

- LILACS (Latin American and Caribbean Health Science Information database, from 1982) using the strategy in Appendix 5. 


\section{Trials Registries and Portals}

We searched the following trials registries and portals to 20 September 2016 using the following search terms.

1. Discoid lupus erythematosus.

2. Skin lupus erythematosus.

3. Cutaneous lupus erythematosus.

- ISRCTN registry (www.controlled-trials.com).

- US National Institutes of Health Ongoing Trials Register (www.clinicaltrials.gov).

- Australian New Zealand Clinical Trials Registry (www.anzctr.org.au).

- World Health Organization International Clinical Trials Registry platform (www.who.int/trialsearch).

- EU Clinical Trials Register (www.clinicaltrialsregister.eu).

\section{Searching other resources}

\section{Handsearching}

We hand searched Index Medicus for studies relating to treatment of discoid lupus erythematosus for the years 1956 to 1966.

\section{References from published studies}

We checked the bibliographies of included studies for further references to relevant trials.

\section{Correspondence}

We approached seven experts in the field of DLE treatment in an attempt to identify other relevant studies, including unpublished trials and dissertations. We asked three pharmaceutical companies for records of unpublished trials.

We approached authors of registered but unpublished trials requesting their results.

\section{Adverse effects}

We did not perform a separate search for adverse effects of the target intervention. However, we recorded all adverse events in Characteristics of included studies and and Characteristics of excluded studies.

\section{Data collection and analysis}

SJ and DW, with PJ's assistance, extracted the data independently and resolved differences by discussion.

MG examined and described the statistical information in individual trials and edited or wrote the sections on measures of treatment effect, data synthesis and unit of analysis issues and created the 'Summary of findings' tables.

\section{Selection of studies}

We (SJ, DW, PJ) screened the titles and abstracts and independently selected them for inclusion or exclusion. We resolved disagreements by discussion.

\section{Data extraction and management}

We (SJ, DW) extracted trial characteristics and outcomes, independently, and recorded the data on a data extraction sheet. We resolved disagreements by discussion.

\section{Assessment of risk of bias in included studies}

We (SJ, DW, MG) assessed the risk of bias and the methodological quality of included studies independently, using the following components of internal and external validity for each included study, as outlined in the Cochrane Handbook of Systematic Reviews of Interventions (Higgins 2011).

a) The method of generation of the randomisation sequence.

b) The method of allocation concealment.

c) Who was blinded and not blinded.

d) The number of participants lost to follow-up and the reasons provided for these losses.

e) Whether outcomes were analysed according to the intention-totreat principle.

f) Comparability of the two treatment groups in each arm.

MG checked assessments in case of discrepancy.

\section{Measures of treatment effect}

For dichotomous outcomes (primary outcomes 1 and 2 and adverse events), results are presented as risk ratios (RR) with 95\% confidence intervals $(\mathrm{Cl})$. Where the first treatment in the comparison is beneficial (RR $>1$ for efficacy outcomes), we presented the number needed to treat for an additional beneficial outcome (NNTB) for any significant outcomes $(P<$ 0.05). We planned to present the number needed to treat for an additional harmful outcome (NNTH) where the first treatment in the comparison is harmful ( $R R>1$ for safety outcomes) for any significant adverse outcomes $(P<0.05)$.

Where results were estimated for individual studies with low numbers of outcomes ( $<10$ in total) or where the total sample size were less than 30 participants, we planned to report the proportion of outcomes in each treatment group, together with a P value from a Fisher's Exact test (obtained using the "tabi" calculator in Stata version 14).

For continuous outcomes (primary outcome 3), we planned to present results in the form of mean differences (with 95\% Cls). Where there were treatment comparisons where studies used different scales for the same outcome, we planned to convert results to standard mean differences (SMD) to allow pooling of results.

\section{Unit of analysis issues}

\section{Cross-over trials}

We followed the guidance provided in Section 16.4.4 of the Cochrane Handbook for Systematic Reviews of Interventions (Higgins 2011). Where no evidence of a carry-over effect was present, analyses of paired differences were presented if these data could be obtained from the trial report. Otherwise, only data from the first treatment period were used. 


\section{Within-patient studies}

Internally controlled trials were analysed using techniques for paired designs (e.g. paired t-test, McNemar's test). Where appropriate, these were included in additional data tables and not pooled with parallel group trials.

\section{Dealing with missing data}

The use of 'intention-to-treat' analysis was reported in the 'Risk of bias' tables of the 'Characteristics of included studies' tables. SJ wrote to five authors and received a response from three authors; some of the investigators in trial registries did not supply contact details.

\section{Assessment of heterogeneity}

We planned to test statistical heterogeneity using the $I^{2}$ statistic (0\% to 40\%: may not be important; $30 \%$ to $60 \%$ : may represent moderate heterogeneity; $50 \%$ to $90 \%$ : may represent substantial heterogeneity; $75 \%$ to $100 \%$ : represents considerable heterogeneity) (Higgins 2011), However, assessment of heterogeneity was not performed as no findings were based on pooled results from two or more trials. If in future updates metaanalyses are performed, the heterogeneity will be quantified using the $I^{2}$ statistic. In cases of substantial heterogeneity $\left(I^{2}>80 \%\right)$, studies will not be pooled and instead reasons for heterogeneity will be explored.

\section{Assessment of reporting biases}

Assessment for reporting bias was not possible in the present review as this contained no pooled results from meta-analyses.

If in future updates of this review there are 10 studies or more of any single intervention, funnel plots will be used to evaluate asymmetry, using Egger's method (Egger 1997), as described in section 10.4.3.1 of theCochrane Handbook for Systematic Reviews of Interventions (Higgins 2011). A degree of reporting bias was identified in Jemec 2009, with details of erythema not reported, although this was described as part of the outcome score. Difference in erythema was not statistically significant.

\section{Data synthesis}

We planned to draw up a synthesis of included trials; however, this was not possible with the data in the studies we found, due to heterogeneity of study methods and interventions. No two trials investigated the same interventions. If in future updates of the review it is possible to pool results then we will use random effects meta-analysis for both dichotomous and continuous outcomes to account for the anticipated heterogeneity between studies.

\section{Subgroup analysis and investigation of heterogeneity}

In the protocol, we had planned to perform subgroup analysis on the following measures: disseminated DLE versus localised DLE; DLE with systemic lupus versus DLE without systemic lupus; histologically proven versus clinically diagnosed DLE; and effect of ethnic group on outcome. However subgroup analysis was not possible in this update.

\section{other}

We planned where possible to calculate cost effectiveness ratios using quality-of-life measures; however, the studies identified did not provide these data.

\section{Sensitivity analysis}

Sensitivity analyses were not carried out as no findings from this review were based on pooled results from two or more studies. If in future updates of this review pooled results are presented, sensitivity analyses will be carried out restricting results to studies assessed as being at low risk of bias for all of the following three domains: allocation concealment; blinding of participants and outcomes assessors; and incomplete outcome data (Higgins 2011).

\section{'Summary of findings' table}

'Summary of findings' tables as detailed in the Cochrane Handbook for Systematic Reviews of Interventions were produced from within Review Manager 5 (RevMan 5) software (Higgins 2011). In these, we have summarised the primary outcomes for the most important comparisons (Summary of findings for the main comparison; Summary of findings 2; Summary of findings 3; Summary of findings 4; Summary of findings 5). Confidence intervals for the corresponding risk were calculated using GRADEpro 2008 software.

\section{RE S U L T S}

\section{Description of studies}

\section{Results of the search}

We retrieved 71 records from the searches for the 2009 review (Jessop 2009), of which two met the criteria for inclusion (Roenigk 1980 and Ruzicka 1992). Literature searches in 2014, 2015, and 2016 yielded a further 155 studies. We identified 12 studies from our searches of trials registers. In total we screened 238 records. We excluded 202 records on the basis of titles and abstracts. Of the remaining 36 records, one article was not available in full text and has been added to studies awaiting classification (Pothinamthong 2012) along with eight trials registry records (see Characteristics of studies awaiting classification). One study is ongoing (see Characteristics of ongoing studies). The remaining 26 articles were assessed in full text for eligibility.

Of the 26 full texts, we excluded 23 studies (14 did not describe outcomes in the DLE group specifically and others were excluded because they referred to photoprotection trials and not drug trials or were not RCTs) (see Characteristics of excluded studies). We included three new studies in this update (Barikbin 2009, Jemec 2009, and Kuhn 2011), giving a total of five included studies altogether (see Characteristics of included studies). We noted that diagnosis of DLE was generally based on clinical judgement in the early studies, but investigators required histological (skin biopsy) confirmation in the three new studies.

Of the nine drug trials of DLE listed in Characteristics of studies awaiting classification, the interventions included etanercept, other biologics, R-salbutamol, pimecrolimus, and an oral retinoid, alitretinoin. Half of the studies were described as complete but results have not yet been published. We attempted to contact two of the investigators, without success. One investigator reported that their study did not include analysis of the subset with DLE.

For a summary of our screening process see Figure 1. 
Figure 1. Study flow diagram

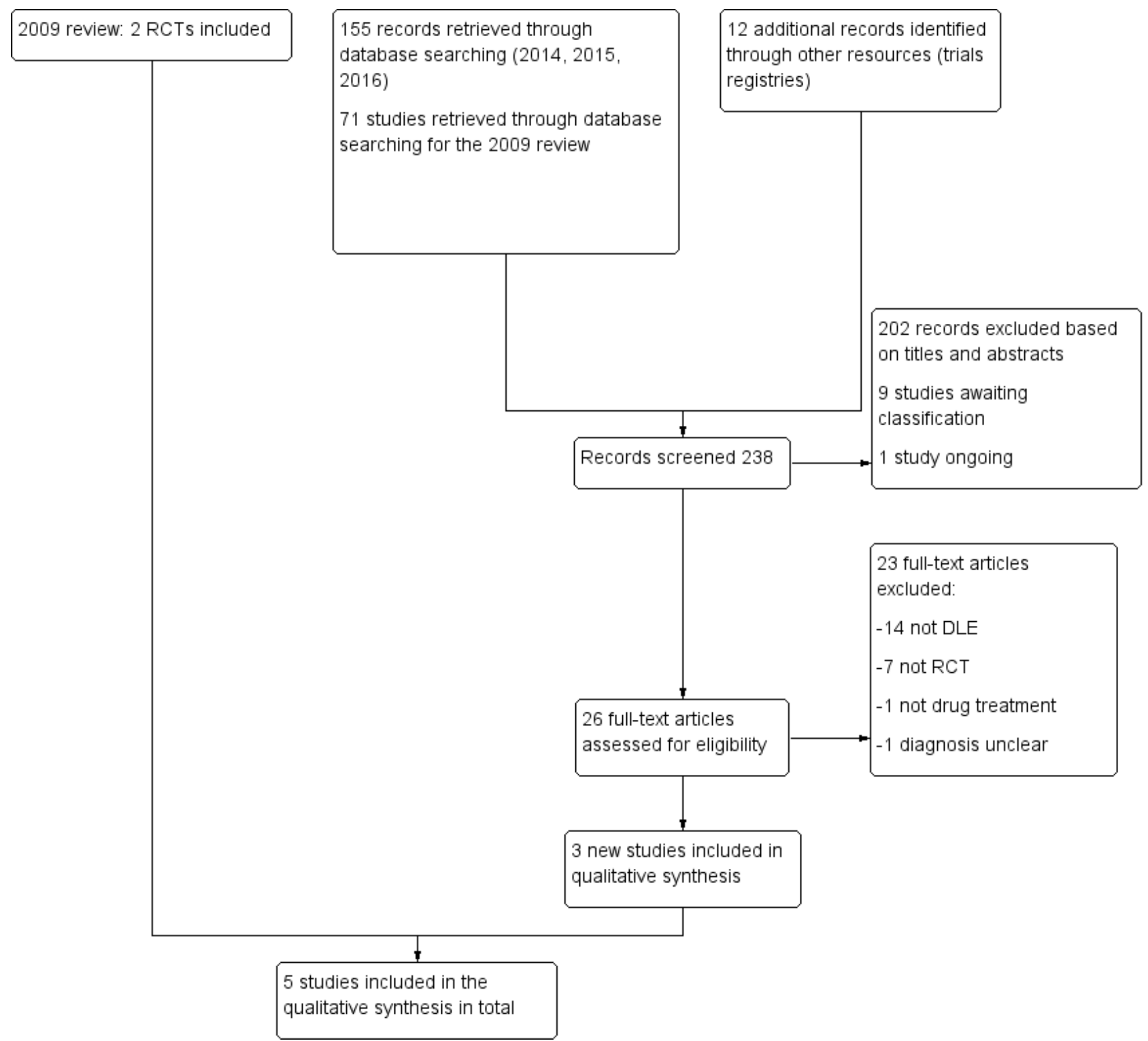

\section{Included studies}

We included five studies, three of which were new. The full details are in the Characteristics of included studies table. There were a total of 197 participants (see sample sizes).

\section{Design}

The first study, involving 78 people, was a double-blind RCT comparing two steroid creams of different potencies (Roenigk 1980). The creams were prepared in the same cream base and identical tubes, and were compared in a 12 -week cross-over trial. A single active lesion on each person was chosen for monitoring. One of the creams was applied for 6 weeks, then the other for a further 6 weeks. Only the outcome prior to cross-over was included in the analysis for this review.

The second trial was a double-blind RCT, over 8 weeks (Ruzicka 1992).
The third trial, was a double-blind RCT, over 8 weeks (Barikbin 2009).

In Jemec 2009, an active agent was compared with placebo, in a double-blind RCT. The creams were identical.

A 2011 trial was a double-blind placebo-controlled RCT, over 12 weeks (Kuhn 2011). The vehicle was used as the placebo, to ensure blinding.

\section{Sample sizes}

There were a total of 197 participants in the five trials: 78 in Roenigk 1980; 58 in Ruzicka 1992; 10 in Barikbin 2009; 37 in Jemec 2009; and 14 in the study by Kuhn 2011. 


\section{Setting}

The setting of Roenigk 1980 was not stated. Ruzicka 1992, Barikbin 2009, Jemec 2009 and Kuhn 2011 were set in specialised lupus clinics, as most people with DLE were attending such clinics.

\section{Participants}

Roenigk 1980 randomised for inclusion 32 men and 61 women, aged 17 to 82 years, from the following ethnic groups: 23 black American, and 25 white American in one group; and 23 black American, and 22 white American in the other. The duration of their disease was very variable (1 to 240 months). There were no significant differences between people in the two arms, in terms of demographics or duration of disease. All participants had chronic DLE. However final number of participants was 78 , (others excluded at onset) and ethnic and gender breakdown of participating group was not supplied.

In Ruzicka 1992, there were 22 men and 36 women, with a mean age of 43.3 years. The ethnic group was not mentioned. All participants had cutaneous lupus, 39 discoid and 19 subacute LE. People with subacute LE were more highly represented in the hydroxychloroquine arm.

In Barikbin 2009 , participants were Iranian, aged 20 to 53, and 7 of the 10 were women. Participants in Jemec 2009 included 28 women and 9 men, aged 34 to 72 . There was no ethnicity provided. In the Kuhn 2011 trial, there were six women and eight men with DLE, with a mean age of $49.8 \pm 5.9$. Ethnicity was not supplied.

\section{Interventions}

Roenigk 1980 compared two topical steroids, fluocinonide $0.05 \%$ (potent steroid) and hydrocortisone 1\% (mild steroid) in the same cream base.

Ruzicka 1992 compared two oral agents, acitretin (a synthetic retinoid) and hydroxychloroquine (an anti-malarial).

Barikbin 2009 compared pimecrolimus 1\% cream with betamethasone 17 -valerate $0.1 \%$ cream.

Jemec 2009 compared salbutamol $0.5 \%$ cream with placebo (same vehicle, so indistinguishable).

Kuhn 2011 compared tacrolimus $0.1 \%$ cream with placebo (vehicle).

\section{Outcomes}

In Roenigk 1980, the outcome was based on the authors' own 5point scale, using a single test site. The investigators used a scale, providing a score of 1 if the lesion became worse, 2 if there was no improvement, 3 if there was a little improvement, 4 if improvement was marked, and 5 if the lesion cleared or showed excellent improvement. There was no assessment by the participants.
Assessment of severity in Ruzicka 1992 was based on an ordinal scale using erythema (redness), infiltration (thickness), and scaling with complete clearing graded as 0 , improvement as 1 , and no change or deterioration as 2. Extent of skin disease and the occurrence of adverse reactions were also documented.

Barikbin 2009 used digital photographs, which were examined by three blinded dermatologists, using a severity score.

Jemec 2009 reported outcomes using the CLASI score, the clinician's global assessment and the participant's global assessment.

Kuhn 2011 used digital photography and a clinical assessment, using a clinical score. They reported adverse events.

Quality-of-life measures or participant global evaluation were not recorded in any of the studies.

\section{Excluded studies}

Details of the 23 excluded studies can be found in the Characteristics of excluded studies table. In 14 studies, participants had systemic or cutaneous lupus, or both, but the group with DLE were not described specifically, so the influence of treatment in DLE could not be established. Seven trials were not randomised. Authors of two excluded RCTs reported results with topical tacrolimus versus topical clobetasol propionate, and clofazimine versus chloroquine diphosphate (Bezerra 2005; Tzung 2007). However, in both studies participants had various forms of cutaneous lupus and results for individual subsets were not reported separately, thus it was not possible to establish the relative benefits of individual treatments in DLE. Avgerinou 2012 was not an RCT and the DLE subset was not reported. Gammon 2011 did not report results for the DLE subset. Manzi 2012, Merrill 2010a, Merrill 2010b, Merrill 2011 and Szepietowski 2013 described people with SLE and did not provide data for the DLE subset. The study of mucosal DLE, comparing tacrolimus ointment and triamcinolone cream by Wang 2015 had major methodology flaws: participants were not blinded and the basis for diagnosis of DLE was not clear (Wang 2015).

We found 12 registered trials in the trial registries. We attempted to contact investigators where the trial was described as completed and had not been published, but very few trial records provided relevant contact details. We received two replies, confirming that people with DLE had not been recorded separately in their trials.

\section{Risk of bias in included studies}

Overall, risk of bias was considered low or unclear for most parameters for the included studies.

See Figure 2 for the risk of bias summary of the judgements for each included study. 
Figure 2. Risk of bias summary: review authors' judgements about each risk of bias item for each included study.

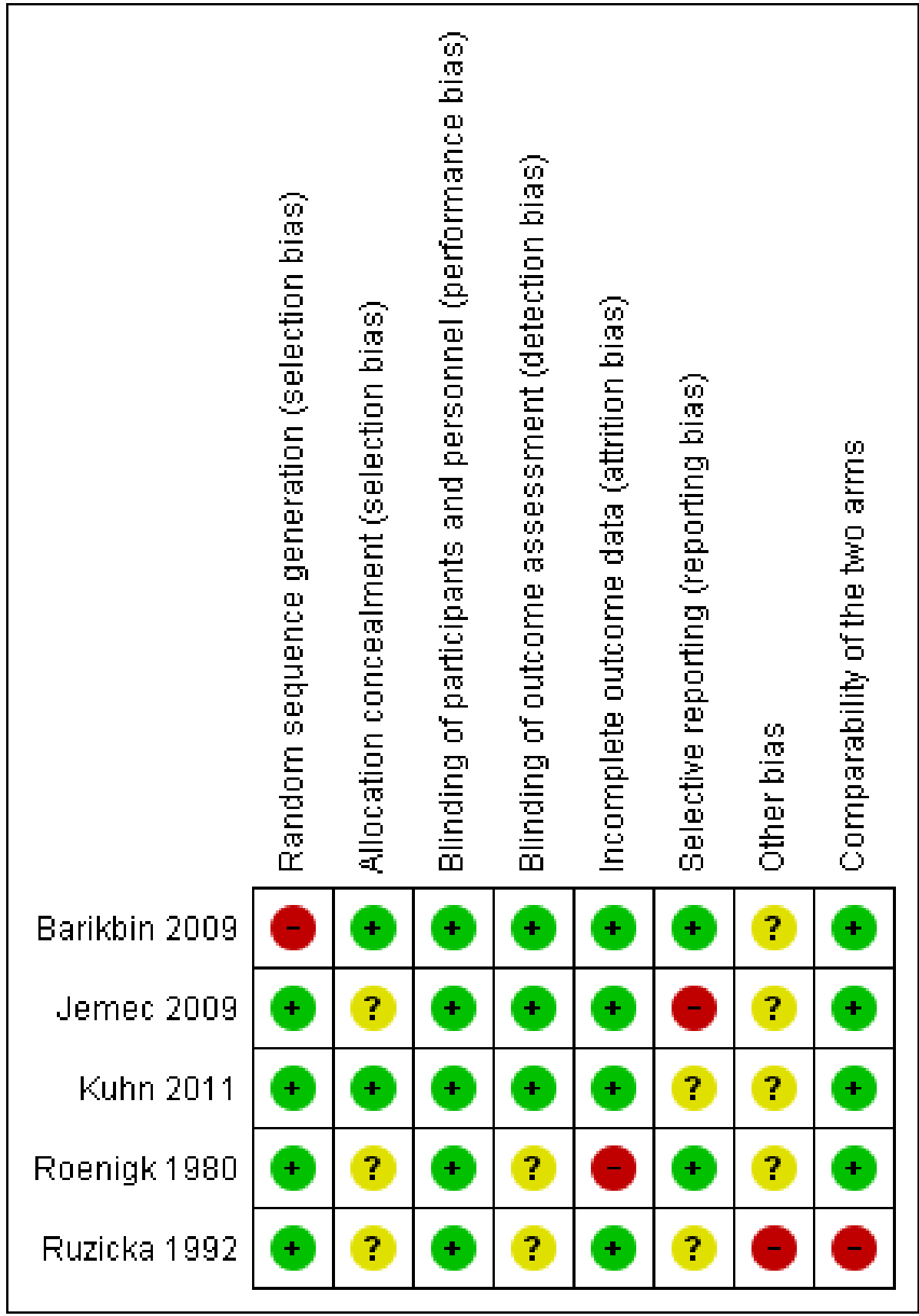

\section{Allocation}

The topical steroid study Roenigk 1980 was randomised and statistical tests for equality confirmed that randomisation was successful; however, no mention was made of allocation concealment. In Ruzicka 1992, comparing hydroxychloroquine and acitretin, participants were randomised but methods taken to conceal the allocation were not stated.

In Barikbin 2009, randomisation was applied by the use of odd and even numbers, (quasi-randomisation), hence was considered high risk of selection bias from an inadequate random sequence generation. However, the method used would not introduce selection bias from allocation concealment as numbers were assigned on the basis of order of referral, so decisions made (re: participation) could not have been made with knowledge of the treatment to be received.

In Jemec 2009, randomisation was generated from a random number list. However, details as to whether the randomisation list was available to recruiting clinicians was not stated (unclear allocation concealment).

In Kuhn 2011, random numbers were computer generated and allocation was conducted by a pharmacist who was independent of the study investigators (adequate concealment of allocation). 


\section{Blinding}

IParticipant blinding was clearly stated in Roenigk 1980; however, blinding of outcome assessors was not described (although the trial was described as double blind). Ruzicka 1992 was described as double-blind, but no details were provided.

Blinding was described in Barikbin 2009, with identical jars of test agents. In Jemec 2009, blinding was described for both assessors and participants. The Kuhn 2011 study similarly used identical containers and both participants and assessors were blinded.

\section{Incomplete outcome data}

In the Roenigk 1980 study, data from 78 people were available for analysis at the end of the first phase (six weeks). Fifteen people dropped out during the first phase, 13 because of non-compliance, and two because of the use of a proscribed drug. Hence, the study was judged at high risk of attrition bias.

The remaining studies were at low risk of attrition bias. In Ruzicka 1992, 51 of 58 participants completed the trial (83\%). Among those given acitretin, four people dropped-out because of side-effects (not detailed), another because of treatment failure, and a sixth due to non-compliance. In the hydroxychloroquine group three people withdrew from the study prematurely because of complete clearing of skin lesions and one because of failure of treatment. Intentionto-treat analysis was used.

There were no withdrawals from the Barikbin 2009 trial.

In the Jemec 2009 study, the numbers contributing to the analyses were not stated but it was clearly stated that an intention-to-treat analysis was carried out.

In the Kuhn 2011 trial, two of the 14 participants with DLE did not complete the trial. Intention to treat analysis was used in a secondary analysis.

Overall, ITT analysis was described in three studies: Barikbin 2009, Jemec 2009, and Kuhn 2011. It was not reported in the other two studies and this was a clear potential risk of bias in the Roenigk 1980 trial, as 15 participants were excluded from final analysis.

\section{Selective reporting}

One study was considered to be at high risk of selective reporting because they authors did not provide details on the impact on erythema (Jemec 2009). In two studies it was unclear if there was selective reporting (Kuhn 2011, Roenigk 1980), while the remaining two studies were judged as low risk (Barikbin 2009, Roenigk 1980), as all expected outcomes were reported.

\section{Other potential sources of bias}

Overall, it was unclear whether studies were at risk of other potential sources of bias, except for Ruzicka 1992 where high clinical heterogeneity was identified; hence, was judged as high risk of other bias. Studies were also assessed separately for 'Comparability of the two arms', see below.

\section{Comparability of the two arms}

The risk of bias was rated as low in four studies. In the Roenigk 1980 trial, the groups were comparable at baseline. The participants in the two arms in the Jemec 2009 study had similar active lesions at baseline (activity scores $1.32 \pm 0.48 \mathrm{vs} 1.11 \pm 0.47$ ). The mean disease severity score was similar between the two groups at baseline in the Barikbin 2009 study. Kuhn 2011 also had comparable arms at baseline.

Ruzicka 1992 included 19 people with subacute cutaneous lupus erythematosus. As people with this form of cutaneous lupus were more strongly represented in the chloroquine group, this might have influenced the outcome of treatment, as people with subacute lupus may have a better response rate. The response rates for discoid lupus and subacute lupus were not described separately. Hence, this study was judged to be at high risk of bias.

We are of the opinion that none of the five studies included in this review are affected by other potential threats to validity, including:

- interim results analysis;

- deviation from study protocol not reflecting clinical practice;

- prerandomisation of the intervention which could affect the result;

- contamination of drugs (pooling of drugs by participants);

- overly wide inclusion criteria for participants;

- use of insensitive instruments to measure outcomes;

- selective reporting of subgroups;

- inappropriate influence of funders.

\section{Effects of interventions}

See: Summary of findings for the main comparison Fluocinonide $0.05 \%$ compared with hydrocortisone $1 \%$; Summary of findings 2 Acitretin $50 \mathrm{mg}$ daily compared with hydroxychloroquine 400 mg daily; Summary of findings 3 Pimecrolimus $1 \%$ compared with betamethasone 17 -valerate $0.1 \%$; Summary of findings 4 Rsalbutamol $0.5 \%$ topical cream compared with placebo; Summary of findings 5 Tacrolimus $0.1 \%$ cream compared with placebo

\section{Primary outcomes}

- Percentage of people with complete resolution of skin lesions (i.e. return to normal skin appearance).

- Percentage of people with clearing of erythema in at least $50 \%$ of lesions (post-inflammatory pigmentation could persist).

- Improvement in patient satisfaction/quality-of-life measures.

\section{Percentage of people with complete resolution of skin lesions (i.e. return to normal skin appearance)}

Note that we accepted the following terms to describe complete resolution: complete clearing, clearing, marked improvement and excellent improvement.

In the Roenigk 1980 study fluocinonide $0.05 \%$ cream appeared to be superior to hydrocortisone $1 \%$ cream (low-potency steroid) in the treatment of discoid lupus erythematosus (Summary of findings for the main comparison). At the 6-week cross-over point, clearing or excellent improvement was found in 10 out of 37 people (27\%) using fluocinonide and in four out of 41 people (10\%) using hydrocortisone (RR $2.77,95 \% \mathrm{Cl} 0.95$ to 8.08 ), 1 study, $n=78$, lowquality evidence) (Analysis 1.1). This shows an absolute benefit of potent steroid of $17 \%$ ( $95 \% \mathrm{Cl} 0$ to $34 \%)$. The quality of evidence for this outcome was judged to be low. 
In the Ruzicka 1992 study, the overall outcome appeared similar in the hydroxychloroquine $400 \mathrm{mg}$ and acitretin $50 \mathrm{mg}$ groups (Summary of findings 2). There was marked improvement or complete clearing in 13 out of $28(46 \%)$ participants given acitretin and in 15 out of $30(50 \%)$ of those on hydroxychloroquine; i.e. there was no significant difference between the two groups (RR 0.93, $95 \% \mathrm{Cl} 0.54$ to 1.59) (Analysis 2.1).The quality of evidence for this outcome was judged to be low.

In the Barikbin 2009 study, those treated with pimecrolimus 1\% had an $86 \%$ reduction in severity score compared to $73 \%$ in the betamethasone 17 -valerate $0.1 \%$ cream group $(P=0.1)$. The number of participants with complete resolution could not be obtained from the paper (Summary of findings 3 ).

In the study by Jemec 2009, the number of participants with complete resolution could not be obtained from the paper (Summary of findings 4).

In the Kuhn 2011 study looking at tacrolimus $0.1 \%$ cream versus placebo (vehicle), no participants with DLE were reported as having experienced complete clearing (Summary of findings 5). The quality of evidence for this outcome was judged to be low.

\section{Percentage of people with clearing of erythema in at least $50 \%$ of lesions (postinflammatory pigmentation could persist)}

In none of the studies was there a measurement of the percentage of participants with clearing of erythema in at least $50 \%$ of lesions.

Roenigk 1980 used a score that included erythema to measure outcome, but did not report the erythema separately. In the Ruzicka 1992 study the effect on erythema was assessed using an ordinal scale where complete clearing was graded as 0 and improvement as 1 , so we take this to mean there was clearing of erythema in at least $50 \%$ of lesions. Erythema showed more marked improvement in the hydroxychloroquine $400 \mathrm{mg}$ group and more people in this group showed complete clearing compared to those taking acitretin $50 \mathrm{mg}$, although the result was not statistically significant. There was complete clearing or marked improvement of erythema in $10 / 24(42 \%)$ of participants in the acitretin group compared to $17 / 25(68 \%)$ in the hydroxychloroquine group ( $\mathrm{RR} 0.61,95 \% \mathrm{Cl} 0.36$ to 1.06) (Analysis 2.2.) The quality of evidence for this outcome was judged to be low.

While Barikbin 2009 recorded erythema in treated sites as part of the clinical score, results for erythema were not reported separately.

In the Jemec 2009 study, there was no significant improvement in erythema, but the actual data were not provided.

In the Kuhn 2011 study, erythema was included in the clinical score, but actual data were not provided.

\section{Improvement in participant satisfaction/quality of life measures}

There was no record of any measurements of participant satisfaction or quality of life in any of the included studies. Jemec 2009 and Kuhn 2011 recorded itch and pain as reported by participants, but no global score or assessment of quality of life.

\section{Secondary outcomes}

- Relapse rate when medication stopped or reduced.
- Prevention of new lesions.

- Adverse effects of medication, leading to discontinuation or significant morbidity.

- Implications for health care costs.

\section{Relapse rate when medication stopped or reduced}

There was no explicit record of relapse rates when medication was stopped in three of the studies. Barikbin 2009 reported that there was no relapse at eight weeks, after stopping the trial medication at four weeks. The trial of Kuhn 2011 reported improvement in skin lesions at four and eight weeks but the benefit was not maintained at 12 weeks. Thus the skin condition had relapsed while the participants were still using the trial cream, tacrolimus $0.1 \%$.

\section{Prevention of new lesions}

In none of the studies was this outcome directly measured.

\section{Adverse effects of medication, leading to discontinuation or significant morbidity}

In the Roenigk 1980 study, adverse effects were minor and were seen in both groups (moderate-quality evidence). Skin irritation occurred in three people using hydrocortisone cream $1 \%$ and burning occurred in two people using fluocinonide cream $0.05 \%$. One person in the hydrocortisone group developed acne. The trial was too short to assess other side-effects, such as skin atrophy (thinning) or capillary damage.

In the Ruzicka 1992 study, compared with those taking hydroxychloroquine $400 \mathrm{mg}$ adverse effects were more frequent in the acitretin group $50 \mathrm{mg}$ and were more severe, with four participants having to discontinue treatment because of adverse effects (moderate-quality evidence). The main clinical adverse effects were dry lips/cheilitis (93\% of the acitretin and $20 \%$ of the hydroxychloroquine group) and gastrointestinal disturbance ( $11 \%$ of the acitretin and $17 \%$ of the hydroxychloroquine group, but no specific information was provided). Laboratory studies revealed changes in triglycerides in both groups, the levels rising from a mean of 1.66 to $2.10 \mathrm{mmol} / \mathrm{l}$ in the acitretin group $(P=0.01)$ and falling from 1.94 to $1.50 \mathrm{mmol} / \mathrm{l}$ in the hydroxychloroquine group $(P=0.02)$. The difference between the two groups was highly significant $(P=0.006)$.

In the Barikbin 2009 study, adverse events were not reported.

In the Jemec 2009 trial there were 39 reported adverse events, 15 in the placebo group and 24 in the salbutamol $0.5 \%$ topical cream group (moderate-quality evidence). None of the adverse events were considered serious and the adverse events did not appear to be related to the trial medication.

Kuhn 2011 reported that five people experienced itching or burning at the site of tacrolimus $0.1 \%$ cream application, sometimes lasting up to six weeks, and one participant developed herpes simplex infection of the lip during treatment (moderate-quality evidence). There were no serious adverse events. No adverse events were experienced by the participants using the placebo cream.

\section{Implications for healthcare costs}

There was no measurement of this outcome in any of the studies. 


\section{DISCUSSION}

\section{Summary of main results}

Five trials are reported in this version of the review, with a total of 197 participants. Three of the studies are new to this update (Barikbin 2009; Jemec 2009; Kuhn 2016). Two of the trials included small numbers of participants (10 in Barikbin 2009 and 14 in Kuhn 2011).

Interventions in the five trials were topical steroids, hydroxychloroquine, acitretin, topical salbutamol, topical tacrolimus, and topical pimecrolimus.

The study of topical steroids provides some evidence that a potent steroid cream, fluocinonide $0.05 \%$, may be superior to lowpotency hydrocortisone $1 \%$ in the complete resolution of discoid lupus erythematosus skin lesions (Summary of findings for the main comparison) (Roenigk 1980). The ideal duration of treatment or likelihood of recurrences following treatment has not been established. Our second primary outcome (percentage of people with clearing of erythema in at least $50 \%$ of lesions) was not measured.

In the comparative trial of hydroxychloroquine $400 \mathrm{mg}$ and acitretin $50 \mathrm{mg}$ (Ruzicka 1992), no difference in efficacy was demonstrated between the two drugs in terms of the primary outcome, with complete resolution of skin lesions reported in $46 \%$ of people taking acitretin and in 50\% of those on hydroxychloroquine. Regarding the second primary outcome, $42 \%$ of participants taking acitretin showed improvement in erythema in at least $50 \%$ of lesions compared with $68 \%$ of the hydroxychloroquine group (Summary of findings 2).

The two studies of calcineurin inhibitors (pimecrolimus $1 \%$ and tacrolimus 0.1\%) (Barikbin 2009; Kuhn 2011), and the study of R-salbutamol $0.5 \%$ topical cream (Jemec 2009), unfortunately included only 61 participants in all and did not report the primary outcomes of the review (Summary of findings 3; Summary of findings 4; Summary of findings 5).

There is some evidence that the trial drugs were free of serious sideeffects, but the short duration of most of the trials does not allow any conclusion about long-term adverse effects of topical steroids. Adverse events were reported in the 12-week tacrolimus $0.1 \%$ study, which was compared to placebo (Kuhn 2011), but none were serious. Roenigk 1980 (fluocinonide cream $0.05 \%$ vs hydrocortisone cream 1\%) was short (six weeks in each arm), and thus side-effects of long-term topical steroid use could not be assessed. Ruzicka 1992 (acitretin $50 \mathrm{mg}$ vs hydroxychloroquine $400 \mathrm{mg}$ ) was the only study that reported discontinuation of participants due to adverse events (four people receiving acitretin discontinued treatment due to dry lips and gastrointestinal symptoms). Jemec 2009 compared topical salbutamol $0.5 \%$ cream with placebo (vehicle), and both groups reported minor adverse events but no serious adverse events. Barikbin 2009 did not present data on adverse events.

We are uncertain about the effect of the interventions on patient satisfaction/quality of life, as this primary outcome was not measured by any of our included studies. The secondary outcomes of preventing new lesions and implications for healthcare costs were not assessed in any study either. Relapse rate when medication was stopped or reduced was reported in Barikbin 2009 and Kuhn 2011. There was no relapse reported in Barikbin 2009 at eight weeks, after stopping the trial medication at four weeks; whilst in Kuhn 2011, participants relapsed by 12 weeks.

\section{Overall completeness and applicability of evidence}

The studies in this review have not addressed all the objectives of the review and do not identify the most effective treatment for DLE in all types of participants.

The studies identified in this review did not address (or addressed inadequately) the relative benefits of many currently used interventions, against each other or against placebo, including hydroxychloroquine (or chloroquine), retinoids, topical steroids, calcineurin inhibitors, methotrexate, azathioprine, lenalidomide or biological agents. Outcome measures failed to address quality of life measures or, in most cases, relapse rate after medication was stopped. Most studies did not report on complete resolution of skin lesions or clearing of erythema either. Although different populations participated in the trials, there were no trials from Asia, Africa, Australia or South America.

\section{Quality of the evidence}

Five trials, involving 197 participants were included. Some primary outcome measures in this review (per cent with complete resolution, percentage with at least $50 \%$ improvement in erythema) were inadequately addressed in the majority of included trials. Furthermore, quality of life was not assessed in any of the five included studies.

Where quantitative results were provided for primary outcomes, the overall quality of the evidence was judged to be low owing to the small size of most of the studies and high risk of bias on important domains such as incomplete outcome data and non-comparability of treatment arms at baseline.

All trials were judged to be at low risk of bias for blinding as they were all double-blind and interventions were identical in appearance (although for two studies, Roenigk 1980 and Ruzicka 1992, the methods used to ensure blinding were not fully described). In four studies the method used to generate the allocation sequence was adequate; however, one study was a quasi-randomised trial where patients were numbered based on time of referral and odd numbered participants were allocated to one treatment and even numbered patients to the other. However, as this study did not include any of our pre-specified primary or secondary outcome measures (instead a total mean severity score was calculated before and after treatment for each participant), no data for this study were presented in our 'Summary of findings' tables. The method used to conceal allocation was also unclear in three of the studies (Jemec 2009, Roenigk 1980; Ruzicka 1992); however, this was judged to be adequate for the other two studies (Barikbin 2009; Kuhn 2011), For four studies, either the numbers analysed were the same as the number recruited or the number of dropouts was very small, so these were judged to be at low risk of bias for incomplete outcome data. However in the Roenigk 1980 study, 15 of the 78 participants did not contribute data towards the primary outcome of clearing or excellent improvement for reasons which may relate to outcome (Summary of findings for the main comparison). Therefore, the quality of evidence on whether there is a difference between fluocinonide and hydrocortisone (lowpotency steroid) with respect to clearing or excellent improvement 
was downgraded by one level. In the trial by Ruzicka 1992, there were more participants with DLE in the hydroxychloroquine group. This created unbalanced treatment groups, which could have influenced the outcomes of clearing or excellent improvement and more than $50 \%$ reduction in erythema (Summary of findings 2 ). We identified no other potential sources of bias that might have had a direct effect on any risk measures presented, However, in many instances our ability to assess these was unclear.

Sample size was judged to be inadequate in all of the included studies, except in the case of Roenigk 1980 with 78 participants (others ranged from 10 to 58 participants per study). This resulted in imprecise measures of effect in instances where these were presented, and evidence was therefore downgraded accordingly in instances where assessment of the quality of evidence is provided (Summary of findings for the main comparison; Summary of findings 2). The small numbers in Ruzicka 1992 may weaken the validity of this study, as does the lack of a control arm, as neither intervention is of established efficacy (Summary of findings 2). The inclusion of people with subacute cutaneous lupus erythematosus is an even greater source of possible error and the results require confirmation.

We also assessed the quality of evidence for adverse events leading to discontinuation or significant morbidity in four out of five comparisons in the 'Summary of findings' tables. The quality of evidence was moderate, with downgrading for imprecision in all comparisons because the evidence was based on only one study with a small number of participants. Furthermore, only Ruzicka 1992 reported participants discontinuing, while the remaining studies only reported minor adverse events. The overall sample size may not have been large enough to identify serious adverse events.

All of the comparisons included in this review were assessed in single studies, which did not allow us to assess consistency of results across studies. As such it was not possible in our review to assess what factors could potentially contribute to differences in findings between studies (heterogeneity).

Indirectness cannot be assessed with confidence in the included studies. As the studies were performed in specialist clinics and most people with DLE are likely to be treated initially at that level, the setting is not out of line with clinical practice.

\section{Potential biases in the review process}

We attempted to conduct a comprehensive search for studies, but the fact that one study has not yet been incorporated may be a source of potential bias (Pothinamthong 2012). Studies in which participants had SLE or undefined cutaneous LE were excluded from the review, but two studies that included participants with DLE and SCLE, (Ruzicka 1992 and Kuhn 2011), were included and this may have introduced a bias. There were 12 studies identified in trials registries, but unpublished and most without contact details. The reviewers were unable to establish the outcome of these trials. After the publication of the original protocol and review (Jessop 2000), a scoring measure was published, and has been widely used for reporting outcomes in DLE (Albrecht 2005). One included study (Jemec 2009) reported outcomes using this scoring measure, but the data were not included in our systematic review because this type of outcome measure was not specified in the review protocol.

\section{Agreements and disagreements with other studies or reviews}

We are not aware of any other relevant reviews or studies.

\section{AUTHORS' CONCLUSIONS}

\section{Implications for practice}

1. There is currently insufficient evidence to guide clinicians in the treatment of severe DLE.

2. Potent steroid cream (fluocinonide) appears to be more effective than low-potency steroid cream (hydrocortisone) in the treatment of discoid lupus erythematosus, although the potent steroid was effective in only about a quarter of the people treated and the low-potency steroid in about $10 \%$.

3. Both hydroxychloroquine and acitretin are associated with marked improvement or clearing in about half of all people treated, but neither drug has been tested against placebo in a randomised clinical trial.

4. At present there is no reliable evidence to support the use of other specific treatments for discoid lupus erythematosus. This should not be seen as evidence that current treatment is ineffective but rather that evidence of effectiveness is lacking. Notably, there have been several large multicentre trials of newer biological agents (Manzi 2012, Merrill 2010a, Merrill 2011, Merrill 2010b, Szepietowski 2013), but unfortunately cutaneous subsets have not been reported separately, so we cannot reach any conclusion about possible benefits of biological agents in DLE. Trials investigating the use of topical biological agents have been registered but no data from such trials is available at present.

5. The study in 'Studies awaiting classification' may alter the conclusions of the review once assessed.

\section{Implications for research}

A combination of small numbers, different outcome measures and short duration reduce the strength of most of these trials and the results need to be confirmed in larger trials.

The early single lesion of DLE may respond well to potent steroid creams. One of the goals should be to prevent scarring as, once it occurs, it is largely irreversible.

Well-planned randomised controlled trials are needed to provide a guide to the treatment of discoid lupus erythematosus. Trials should not mix different types of lupus together and ideally the diagnosis should be confirmed with a skin biopsy. There is a need for trials comparing topical steroids with other agents. The outcome measures should be stated clearly and should include participants' views and information about scarring. If the CLASI scoring system is adopted widely, more consistent outcome measures may be obtained. If future trials were to include a core set of outcome measures, following the recent COUSIN initiative from the Cochrane Skin Group, there is a much greater likelihood of being able to pool results from multiple studies in future updates of this review.

Also, the trials should be of sufficient duration to allow for seasonal variation and capture of relapses (suggested minimum of 9 months). Recurrence rate on and off treatment and occurrence 
of side-effects should be documented. Priorities for further studies, involving larger numbers, are as follows.

1. Potent topical steroid versus chloroquine or hydroxychloroquine (these antimalarials are cheap and widely available in many countries).

2. Potent topical steroid versus oral retinoid (more expensive and can cause birth defects).

3. Potent topical steroid versus methotrexate (cheap and available but possible liver and bone marrow toxicity, so needs careful monitoring).

4. Potent topical steroid versus lenalidomide (similar to thalidomide, but possibly with a better safety profile).
5. Potent topical steroids or chloroquine versus biological agents.

\section{ACKNOWLEDGEMENTS}

This review was performed with the guidance and assistance of members of the Cochrane Skin Group, Nottingham, UK, in particular Hywel Williams, Finola Delamere, Laura Prescott, Helen Scott, Tina Leonard, and Kayode Adetugbo.

The editorial base would like to thank Jennifer Humbles (consumer), for reading the review, and the following people, who were the external referees for this review: Sam Gibbs, Enno Schmidt, Yong Cui, Thomas Chu, Ching-Chi Chi, Ankur Barua. 


\section{R E F E RE N CES}

\section{References to studies included in this review}

Barikbin 2009 \{published data only\}

Barikbin B, Givrad S, Yousefi M, Eskandari F. Pimecrolimus $1 \%$ cream versus betamethasone 17 -valerate $0.1 \%$ cream in the treatment of facial discoid lupus erythematosus: a double-blind, randomized pilot study. Clinical and Experimental Dermatology 2009;34(7):776-80. [PUBMED: 19456797]

\section{Jemec 2009 \{published data only\}}

Jemec GB, Ullman S, Goodfield M, Bygum A, Olesen AB, BerthJones J, et al. A randomized controlled trial of R-salbutamol for topical treatment of discoid lupus erythematosus. British Journal of Dermatology 2009;161(6):1365-70. [PUBMED: 19681862]

\section{Kuhn 2011 \{published data only\}}

Kuhn A, Gensch K, Haust M, Schneider SW, Bonsmann G, Gaebelein-Wissing N, et al. Efficacy of tacrolimus $0.1 \%$ ointment in cutaneous lupus erythematosus: a multicenter, randomized, double-blind, vehicle-controlled trial. Journal of the American Academy of Dermatology 2011;65(1):54-64. [PUBMED: 21501887]

Roenigk 1980 \{published data only\}

* Roenigk HH, Martin JS, Eichorn P, Gilliam JN. Discoid lupus erythematosus. Diagnostic features and evaluation of topical corticosteroid therapy. Cutis; Cutaneous Medicine for the Practitioner 1980;25(3):281-5. [PUBMED: 6987043]

Ruzicka 1992 \{published data only\}

* Ruzicka T, Sommerburg C, Goerz G, Kind P, Mensing H. Treatment of cutaneous lupus erythematosus with acitretin and hydroxychloroquine. British Journal of Dermatology 1992;127(5):513-8. [PUBMED: 1467292]

\section{References to studies excluded from this review}

\section{Avgerinou 2012 \{published data only\}}

Avgerinou G, Papafragkaki DK, Nasiopoulou A, Arapaki A, Katsambas A, Stavropoulos PG. Effectiveness of topical calcineurin inhibitors as monotherapy or in combination with hydroxychloroquine in cutaneous lupus erythematosus. Journal of the European Academy of Dermatology and Venereology: JEADV 2012;26(6):762-7. [PUBMED: 21707772]

\section{Bezerra 2005 \{published data only\}}

Bezerra EL, Vilar MJ, de Trindade Neto PB, Sato El. Doubleblind, randomized, controlled clinical trial of clofazimine compared with chloroquine in patients with systemic lupus erythematosus. Arthritis and Rheumatism 2005;52(10):3073-8. [PUBMED: 16200586]

\section{Bjornberg 1963 \{published data only\}}

* Bjornberg A, Hellgren L. Treatment of chronic discoid lupus erythematosus with fluocinolone acetonide ointment. British Journal of Dermatology 1963;75:156-60. [PUBMED: 13971327]
Furie 2015a \{published data only\}

Furie RA, Leon G, Thomas M, Petrie MA, Chu AD, Hislop C, et al. A phase 2, randomised, placebo-controlled clinical trial of blisibimod, an inhibitor of B cell activating factor, in patients with moderate-to-severe systemic lupus erythematosus, the PEARL-SC study. Annals of the Rheumatic Diseases 2015;74(9):1667-75. [PUBMED: 24748629]

Furie 2015b \{published data only\}

Furie R, Das M, Li D, Smythe S, Mathura E, Becker P. Repository corticotropin injection (H.P. acthar gel) attenuates disease activity in patients with persistently active systemic lupus erythematosus (SLE) requiring corticosteroids. Arthritis and Rheumatology 2015;67:no pagination. [CENTRAL: CN-01162652; EMBASE: 72094616]

\section{Gammon 2011 \{published data only\}}

Gammon B, Hansen C, Costner MI. Efficacy of mycophenolate mofetil in antimalarial-resistant cutaneous lupus erythematosus. Journal of the American Academy of Dermatology 2011;65(4):717-21. [PUBMED: 21641078]

Islam 2012 \{published data only\}

Islam NM, Hossain M, Haq SA, Alam NM, Ten Klooster PM, Rasker JJ. Efficacy and safety of methotrexate in articular and cutaneous manifestations of systemic lupus erythematosus. International Journal of Rheumatic Diseases 2012;15(1):62-8. [PUBMED: 22324948]

\section{Khamashta 2016 \{published data only\}}

Khamashta M, Merrill JT, Werth VP, Furie R, Kalunian K, Illei GG, et al. Sifalimumab, an anti-interferon-a monoclonal antibody, in moderate to severe systemic lupus erythematosus: A randomised, double-blind, placebo-controlled study. Annals of Rheumatic Diseases 2016;75(11):1909-16. [PUBMED: 27009916]

Kraak 1965 \{published data only\}

* Kraak JH, van Ketel W, Prakken JR, Van Zwet W. The value of hydroxychloroquine (Plaquenil) for the treatment of chronic discoid lupus erythematosus; a double blind trial. Dermatologica 1965;130:293-305. [PUBMED: 14333636]

\section{Kuhn 2011a \{published data only\}}

Kuhn A, Gensch K, Haust M, Meuth AM, Boyer F, Dupuy P, et al. Photoprotective effects of a broad-spectrum sunscreen in ultraviolet-induced cutaneous lupus erythematosus: a randomized, vehicle-controlled, double-blind study. Journal of the American Academy of Dermatology 2011;64(1):37-48. [PUBMED: 21167404]

\section{Kuhn 2016 \{published data only\}}

Kuhn A, Landmann A, Patsinakidis N, Ruland V, Nozinic S, Perusquia Ortiz AM, et al. Fumaric acid ester treatment in cutaneous lupus erythematosus (SLE): a prospective, openlabel, phase II pilot study. Lupus 2016;25(12):1357-64. [PUBMED: 27147621] 


\section{Madan 2010 \{published data only\}}

Madan V, August PJ, Chalmers RJ. Efficacy of topical tacrolimus $0.3 \%$ in clobetasol propionate $0.05 \%$ ointment in therapyresistant cutaneous lupus erythematosus: a cohort study. Clinical and Experimental Dermatology 2010;35(1):27-30. [PUBMED: 19549244]

\section{Manzi 2012 \{published data only\}}

Manzi S, Sánchez-Guerrero J, Merrill JT, Furie R, Gladman D, Navarra SV, et al. Effects of belimumab, a B lymphocyte stimulator-specific inhibitor, on disease activity across multiple organ domains in patients with systemic lupus erythematosus: combined results from two phase III trials. Annals of the Rheumatic Diseases 2012;71(11):1833-8. [PUBMED: 22550315]

\section{Merrill 2010a \{published data only\}}

Merrill JT, Burgos-Vargas R, Westhovens R, Chalmers A, D'Cruz D, Wallace DJ, et al. The efficacy and safety of abatacept in patients with non-life-threatening manifestations of systemic lupus erythematosus: results of a twelve-month, multicenter, exploratory, phase IIb, randomized, double-blind, placebocontrolled trial. Arthritis and Rheumatism 2010;62(10):3077-87. [PUBMED: 20533545]

\section{Merrill 2010b \{published data only\}}

Merrill JT, Neuwelt CM, Wallace DJ, Shanahan JC, Latinis KM, Oates JC, et al. Efficacy and safety of rituximab in moderatelyto-severely active systemic lupus erythematosus: the randomized, double-blind, phase II/III systemic lupus erythematosus evaluation of rituximab trial. Arthritis and Rheumatism 2010;62(1):222-33. [PUBMED: 20039413]

\section{Merrill 2011 \{published data only\}}

Merrill JT, Wallace DJ, Petri M, Kirou KA, Yao Y, White WI, et al. Safety profile and clinical activity of sifalimumab, a fully human anti-interferon alpha monoclonal antibody, in systemic lupus erythematosus: A phase I, multicentre, doubleblind randomised study. Annals of the Rheumatic Diseases 2011;70(11):1905-13. [PUBMED: 21798883]

Ordi-Ros 2000 \{published data only\}

Ordi-Ros J, Cortes F, Cucurull E, Mauri M, Bujan S, Vilardell M. Thalidomide in the treatment of cutaneous lupus refractory to conventional therapy. Journal of Rheumatology 2000;27(6):1429-33. [PUBMED: 10852265]

\section{Szepietowski 2013 \{published data only\}}

Szepietowski JC, Nilganuwong S, Wozniacka A, Kuhn A, Nyberg F, van Vollenhoven RF, et al. Phase I, randomized, double-blind, placebo-controlled, multiple intravenous, doseascending study of sirukumab in cutaneous or systemic lupus erythematosus. Arthritis and Rheumatism 2013;65(10):2661-71. [PUBMED: 23896980]

\section{Thivolet 1990 \{published data only\}}

Thivolet J, Nicolas JF, Kanitakis J, Lyonnet S, Chouvet B. Recombinant interferon alpha $2 \mathrm{a}$ is effective in the treatment of discoid and subacute cutaneous lupus erythematosus. British Journal of Dermatology 1990;122(3):405-9. [PUBMED: 2182099]
Tzung 2007 \{published data only\}

Tzung TY, Liu YS, Chang HW. Tacrolimus vs clobetasol propionate in the treatment of facial cutaneous lupus erythematosus: a randomized, double-blind, bilateral comparison study. British Journal of Dermatology 2007;156(1):163-201.

\section{Wang 2015 \{published data only\}}

Wang X, Zhang L, Luo J, Wu Z, Mei Y, Wang Y, et al. Tacrolimus $0.03 \%$ ointment in labial discoid lupus erythematosus: a randomized controlled clinical trial. Journal of Clinical Pharmacology 2015;55(11):1221-8. [PUBMED: 25951426]

Yokogawa 2015 \{published data only\} Yokogawa N, Takahashi T, Sato T, Yokota N. A double-blind, randomized, parallel-group study of hydroxychloroquine on cutaneous lupus erythematosus in Japan. Arthritis and Rheumatology 2015;67:no pagination. [CENTRAL: CN-01162609; EMBASE: 72095665]

\section{Zhong 2013 \{published data only\}}

Zhong LLD, Bian ZX, Gu JH, Zhou X, Tian Y, Mao JC, et al. Chinese herbal medicine (Zi shen ging) for mild to moderate systemic lupus erythematosus: A pilot prospective single-blinded randomised controlled study. Evidencebased Complementary and Alternative Medicine : ECAM 2013;2013:327245. [CENTRAL: CN-00906171; EMBASE: 2013362297]

\section{References to studies awaiting assessment}

NCT00001680 \{unpublished data only\}

NCT00001680. A pilot trial of topical thalidomide for the management of chronic discoid lupus erythematosus. clinicaltrials.gov/ct2/show/NCT00001680 date first received: 3 November 1999.

\section{NCT00222183 \{unpublished data only\}}

NCT00222183. Cutaneous lupus erythematosus and elidel. clinicaltrials.gov/ct2/show/NCT00222183 date first received: 19 September 2005.

NCT00625157 \{unpublished data only\}

NCT00625157. Efficacy and safety of ASF-1096 cream 0.5\% in the treatment of discoid lupus erythematosus (DLE) lesions (2). clinicaltrials.gov/ct2/show/NCT00625157 date first received: 20 February 2008.

NCT00625521 \{published data only (unpublished sought but not used)\}

NCT00625521. Efficacy and safety of ASF-1096 cream 0.5\% in the treatment of discoid lupus erythematosus (DLE) lesions. clinicaltrials.gov/ct2/show/NCT00625521 date first received: 20 February 2008.

\section{NCT01164917 \{unpublished data only\}}

NCT01164917. Safety study of AMG 811 in subjects with discoid lupus erythematosus. clinicaltrials.gov/ct2/show/NCT01164917 date first received: 15 July 2010. 


\section{NCT01300208 \{unpublished data only\}}

NCT01300208. To evaluate the preliminary safety, tolerability, pharmacokinetics, pharmacodynamics and efficacy of CC-11050 in subjects with discoid lupus erythematosus and subacute cutaneous lupus erythematosus. clinicaltrials.gov/ct2/show/ NCT01300208 date first received: 18 October 2010.

NCT01407679 \{unpublished data only\}

NCT01407679. Efficacy and safety of oral alitretinoin (Toctino $\left.{ }^{\circledR}\right)$ in the treatment of patients with cutaneous lupus erythematosus (AliCLE). clinicaltrials.gov/ct2/show/ NCT01407679 date first received: 1 August 2011.

\section{NCT01597050 \{published data only\}}

* NCT01597050. Safety and efficacy of topical R333 in patients with discoid lupus erythematosus (DLE) and systemic lupus erythematosus (SLE) lesions (SKINDLE). clinicaltrials.gov/ct2/ show/NCT01597050 date first received: 9 May 2012.

\section{Pothinamthong 2012 \{published data only\}}

Pothinamthong P, Janjumratsang P. A comparative study in efficacy and safety of $0.1 \%$ tacrolimus and $0.05 \%$ clobetasol propionate ointment in discoid lupus erythematosus by modified cutaneous lupus erythematosus disease area and severity index. Journal of the Medical Association of Thailand= Chotmaihet Thangphaet 2012;95(7):933-40. [PUBMED: 22919989]

\section{References to ongoing studies}

NCT02927457 \{unpublished data only\}

NCT02927457. Safety, tolerability, pharmacokinetics, pharmacodynamics and clinical effect of GSK2646264 in cutaneous lupus erythematosus patients [A doubleblind (sponsor unblinded) study to investigate safety, tolerability, pharmacokinetics, pharmacodynamics and clinical effect of repeat dosing of GSK2646264 in cutaneous lupus erythematosus patients]. clinicaltrials.gov/ct2/show/ NCT02927457 Date first received: 30 August 2016.

\section{Additional references}

\section{Albrecht 2005}

Albrecht J, Taylor L, Berlin JA, Dulay S, Ang G, Fakharzadeh S, et al. The CLASI (Cutaneous Lupus Erythematosus disease Area and Severity Index): an outcome instrument for cutaneous lupus erythematosus. Journal of Investigative Dermatology 2005;125(5):889-94. [PUBMED: 16297185]

\section{Artuz 1996}

Artuz F, Lenk N, Deniz N, Alli N. Efficacy of sulphasalazine in discoid lupus erythematosus. International Journal of Dermatology 1996;35(10):746-8. [PUBMED: 8891833]

\section{Brodthagen 1959}

Brodthagen $\mathrm{H}$. Hydroxychloroquine (Plaquenil) in the treatment of lupus erythematosus. Acta Dermato-venereologica 1959;39:233-7. [PUBMED: 13804646]

\section{Callen 1982}

Callen JP. Chronic cutaneous lupus erythematosus. Clinical, laboratory, therapeutic, and prognostic examination of 62 patients. Archives of Dermatology 1982;118(6):412-6. [PUBMED: 7092253]

\section{Callen 1997}

Callen JP. Management of antimalarial-refractory cutaneous lupus erythematosus. Lupus 1997;6(2):203-8. [PUBMED: 9061669]

\section{Chasset 2015}

Chasset F, Francès C, Barete S, Amoura Z, Arnaud I. Influence of smoking on the efficacy of antimalarials in cutaneous lupus: a meta-analysis of the literature. Journal of the American Academy of Dermatology 2015;72(4):634-9. [PUBMED: 25648824]

\section{Coburn 1982}

Coburn PR, Shuster S. Dapsone and discoid lupus erythematosus. British Journal of Dermatology 1982;106(1):105-6. [PUBMED: 7059497]

\section{Cortés-Hernández 2012}

Cortés-Hernández J, Torres-Salido M, Castro-Marrero J, Vilardell-Tarres M, Ordi-Ros J. Thalidomide in the treatment of refractory cutaneous lupus erythematosus: prognostic factors of clinical outcome. British Journal of Dermatology 2012;166(3):616-23. [PUBMED: 21999437]

\section{Dalziel 1986}

Dalziel K, Going S, Cartwright PH, Marks R, Beveridge GW, Rowell NR. Treatment of chronic discoid lupus erythematosus with an oral gold compound (auranofin). British Journal of Dermatology 1986;115(2):211-6. [PUBMED: 3091062]

\section{Egger 1997}

Egger M, Davey Smith G, Schneider M, Minder C. Bias in meta-analysis detected by a simple, graphical test. BMJ 1997;315(7109):629-634. [PUBMED: 9310563]

\section{Feldman 1994}

Feldman R, Salomon D, Saurat JH. The association of the two antimalarials chloroquine and quinacrine for treatmentresistant chronic and subacute cutaneous lupus erythematosus. Dermatology 1994;189(4):425-7. [PUBMED: 7873836]

\section{Fernandes 2015}

Fernandes MS, Girisha BS, Viswanathan N, Sripathi H, Noronha TM. Discoid lupus erythematosus with squamous cell carcinoma: a case report and review of the literature in Indian patients. Lupus 2015;24(14):1562-6. [PUBMED: 26251401]

\section{Geamanu 2014}

Geamanu Panca A, Popa-Cherecheanu A, Marinescu B, Geamănu CD, Voinea LM. Retinal toxicity associated with chronic exposure to hydroxychloroquine and its ocular screening. Review. Journal of Medicine and Life 2014;7(3):322-326. [PUBMED: 25408748] 


\section{Goldberg 2015}

Goldberg R, Irving P. Toxicity and response to thiopurines in patients with inflammatory bowel disease. Expert Review of Gastroenterology \& Hepatology 2015;9(7):891-900. [PUBMED: 25915575]

\section{Goldman 1953}

Goldman L, Cole DP, Preston RH. Chloroquine diphosphate in treatment of discoid lupus erythematosus. Journal of the American Medical Association 1953;152(15):1428-9. [PUBMED: 13061294]

\section{Goldstein 1994}

Goldstein E, Carey W. Discoid lupus erythematosus: successful treatment with oral methotrexate. Archives of Dermatology 1994;130(7):938-9. [PUBMED: 8024288]

\section{Hasper 1983}

Hasper MF. Chronic cutaneous lupus erythematosus. Thalidomide treatment of 11 patients. Archives of Dermatology 1983;119(10):812-5. [PUBMED: 6614949]

\section{Higgins 2011}

Higgins JPT, Green S (editors). Cochrane Handbook for Systematic Reviews of Interventions. Version 5.1.0 [updated March 2011]. The Cochrane Collaboration, 2011. Available from handbook.cochrane.org.

\section{Jansen 1965}

Jansen GT, Dillaha CJ, Honeycutt WM. Discoid lupus erythematosus. Is systemic treatment necessary?. Archives of Dermatology 1965;92(3):283-5. [PUBMED: 11851251]

\section{Khandpur 2004}

Khandpur S, Sharma VK, Sumanth K. Topical immunomodulators in dermatology. Journal of Postgraduate Medicine 2004;50(2):131-9. [PUBMED: 15235214]

\section{Kierland 1953}

Kierland RR, Brunsting LA, O'Leary PA. Quinacrine hydrochloride (atabrine) in the treatment of lupus erythematosus. Archives of Dermatology and Syphilology 1953;68(6):651-9. [PUBMED: 13103808]

\section{Knop 1983}

Knop J, Bonsmann G, Happle R, Ludolph A, Matz DR, Mifsud EJ, et al. Thalidomide in the treatment of 60 cases of chronic discoid lupus erythematosus. British Journal of Dermatology 1983;108:461-6.

\section{Kraak 1964}

Kraak JH. Local treatment of chronic lupus erythematosus with triamcinolone injections [Lokale behandeling van chronische (lupus) erythematodes]. Nederlands Tijdschrift voor Geneeskunde 1964;108:1305-6. [PUBMED: 14177187]

\section{Kreuter 2009}

Kreuter A, Gaifullina R, Tigges C, Kirschke J, Altmeyer P, Gambichler T. Lupus erythematosus tumidus: response to antimalarial treatment in 36 patients with emphasis on smoking. Archives of Dermatology 2009;145(3):244-8. [PUBMED: 19289751]

\section{Kuhn 2014}

Kuhn A, Landmann A. The classification and diagnosis of cutaneous lupus erythematosus. Journal of Autoimmunity 2014;48-49:14-9. [PUBMED: 24486120]

\section{Lindskov 1986}

Lindskov R, Reymann F. Dapsone in the treatment of cutaneous lupus erythematosus. Dermatologica 1986;172(4):214-7. [PUBMED: 3519302]

\section{Mackey 1974}

Mackey JP, Barnes J. Clofazimine in the treatment of discoid lupus erythematosus. British Journal of Dermatology 1974;91(1):93-6. [PUBMED: 4851057]

\section{Maguire 1962}

Maguire A. Amodiaquine hydrochloride in the treatment of chronic discoid lupus erythematosus. Lancet 1962;1(7231):665-7. [PUBMED: 14468396]

\section{Marsden 1968}

Marsden CW. Fluocinolone acetonide 0.2 per cent cream a co-operative clinical trial. British Journal of Dermatology 1968;80(9):614-7. [PUBMED: 4877599]

\section{Martinez 1992}

Martinez J, de Misa RF, Torrelo A, Ledo A. A low-dose intralesional interferon alfa for discoid lupus erythematosus. Journal of the American Academy of Dermatology 1992;26 (3 Pt 2):494-6. [PUBMED: 1564159]

\section{Naafs 1985}

Naafs B, Faber WR. Thalidomide therapy. An open trial. International Journal of Dermatology 1985;24(2):131-4. [PUBMED: 2985516]

\section{Norris 2005}

Norris DA. Mechanisms of action of topical therapies and the rationale for combination therapy. Journal of the American Academy of Dermatology 2005;53(1 Suppl 1):S17-25. [PUBMED: 15968260]

\section{Okon 2014}

Okon L, Rosenbach M, Krathen M, Rose M, Propert K, Okawa J, et al. Lenalidomide in treatment-refractory cutaneous lupus erythematosus: Efficacy and safety in a 52-week trial. Journal of American Academy of Dermatology 2014;70(3):583-4. [PUBMED: 24528907]

\section{Ortiz 2013}

Ortiz NE, Nijhawan RI, Weinberg JM. Acitretin. Dermatologic Therapy 2013;26(5):390-9. [PUBMED: 24099069]

\section{Prakken 1961}

Prakken JR. Difficulty in judging the value of therapy. Observations in connection with reports on the treatment of chronic lupus erythematosus [Oorspronkelijke Stukken. Het moeilijke oordeel over de waarde van een therapie]. Nederlands 
Tijdschrift voor Geneeskunde 1961;105:971-6. [PUBMED: 13737707]

\section{Rainsford 2015}

Rainsford KD, Parke AL, Clifford-Rashotte M, Kean WF. Therapy and pharmacological properties of hydroxychloroquine and chloroquine in systemic lupus erythematosus, rheumatoid arthritis and related diseases. Inflammopharmacology 2015;23(5):231-69. [PUBMED: 26246395]

\section{Rees 1963}

Rees RB, Maibach HI. Chloroquine. A review of reactions and dermatologic indications. Archives of Dermatology 1963;88:280-9. [PUBMED: 14043620]

\section{Reyman 1974}

Reyman F. Treatment of discoid lupus erythematosus with betametasone-valerate cream 1 percent. Dermatologica 1974;149(2):65-8. [PUBMED: 4615953]

\section{Rodriguez-Castellanos 1995}

Rodriguez-Castellanos MA, Barba Rubio J, Barba Gomez JF, Gonzalez Mendoza A. Phenytoin in the treatment of discoid lupus erythematosus. Archives of Dermatology 1995;131(5):620-1. [PUBMED: 7741559]

\section{Rothfield 1963}

Rothfield NF, March C, Miescher P, McEwen C. Chronic discoid lupus erythematosus - a study of 65 patients and 65 controls. New England Journal of Medicine 1963;269:1155-61.

\section{Ruzicka 1988}

Ruzicka T, Meurer M, Bieber T. Efficiency of acitretin in the treatment of cutaneous lupus erythematosus. Archives of Dermatology 1988;124(6):897-902. [PUBMED: 2967674]

\section{Schroeder 2007}

Schroeder M, Zouboulis CC. All-trans-retinoic acid and 13cis-retinoic acid: pharmacokinetics and biological activity in different cell culture models of human keratinocytes. Hormone Metabolism Research 2007;39(2):136-40. [PUBMED: 17326009]

\section{Shornick 1991}

Shornick JK, Formica N, Parke AL. Isotretinoin for refractory lupus erythematosus. Journal of the American Academy of Dermatology 1991;24(1):49-52. [PUBMED: 1999529]

\section{Smith 1986}

Smith JF. Intralesional triamcinolone as an adjunct to antimalarial drugs in the treatment of chronic discoid lupus erythematosus. British Journal of Dermatology 1962;74:350-3. [PUBMED: 13989464]

\section{Tsellos 2008}

Tzellos TG, Kouvelas D. Topical tacrolimus and pimecrolimus in the treatment of cutaneous lupus erythematosus: an evidence-

\section{CHARACTERISTICS OF STUDIES}

Characteristics of included studies [ordered by study ID] based evaluation. European Journal of Clinical Pharmacology 2008;64(4):337-41. [PUBMED: 18157526]

\section{Tsokos 1985}

Tsokos GC, Caughman SW, Klippel JH. Successful treatment of generalized discoid skin lesions with azathioprine. Its use in a patient with systemic lupus erythematosus. Archives of Dermatology 1985;121(10):1323-5. [PUBMED: 4037829]

\section{Usmani 2007}

Usmani N, Goodfield M. Efalizumab in the treatment of discoid lupus erythematosus. Archives of Dermatology 2007;143(7):873-7. [PUBMED: 17638731]

\section{Vasquez 2013}

Vasquez R, Wang D, Tran QP, Adams-Huet B, Chren MM, Costner MI, et al. A multicentre, cross-sectional study on quality of life in patients with cutaneous lupus erythematosus. British Journal of Dermatology 2013;168(1):145-53. [PUBMED: 22708924]

\section{Weinblatt 2013}

Weinblatt ME. Methotrexate in rheumatoid arthritis: a quarter century of development. Transactions of the American Clinical and Climatological Association 2013;124:16-25. [PUBMED: 23874006]

\section{Wollina 2007}

Wollina U, Hansel G. The use of topical calcineurin inhibitors in lupus erythematosus: an overview. Journal of the European Academy of Dermatology and Venereology: JEADV 2008;22(1):1-6. [PUBMED: 18005117]

\section{Zhou 2013}

Zhou S, Wang F, Hsieh TC, Wu JM, Wu E. Thalidomide - a notorious sedative to a wonder anticancer drug. Current Medicinal Chemistry 2013;20(33):4102-8. [PUBMED: 23931282]

\section{References to other published versions of this review Jessop 2000}

Jessop S, Whitelaw D, Jordaan F. Drugs for discoid lupus erythematosus. Cochrane Database of Systematic Reviews 2000, Issue 2. [DOI: 10.1002/14651858.CD002954]

\section{Jessop 2009}

Jessop S, Whitelaw DA, Delamere FM. Drugs for discoid lupus erythematosus. Cochrane Database of Systematic Reviews 2009, Issue 4. [DOI: 10.1002/14651858.CD002954.pub2]

* Indicates the major publication for the study 
Barikbin 2009

\begin{tabular}{ll}
\hline Methods & RCT, 8 weeks of treatment, with further 8-week follow-up. \\
\hline Participants & 10 adults with facial DLE; diagnosis clinical and histological. \\
\hline Interventions & Pimecrolimus $1 \%$ vs betamethasone 17 -valerate $0.1 \%$ cream, twice daily. \\
\hline Outcomes & Digital photographs; clinical assessment by 3 blinded dermatologists, using a clinical score* \\
\hline Notes & $\begin{array}{l}{ }^{*} \text { Reported erythema and adverse events. Did not report complete resolution or participant satisfac- } \\
\text { tion. }\end{array}$
\end{tabular}

\section{Risk of bias}

\begin{tabular}{lll}
\hline Bias & Authors' judgement & Support for judgement \\
\hline $\begin{array}{l}\text { Random sequence genera- } \\
\text { tion (selection bias) }\end{array}$ & High risk & $\begin{array}{l}\text { Quote: "all patients with odd numbers were allocated to group A (pime- } \\
\text { crolimus } 1 \% \text { ) and all patients with even numbers to group B (betamethasone } \\
\text { valerate } 0.1 \% " .\end{array}$ \\
\hline $\begin{array}{l}\text { Allocation concealment } \\
\text { (selection bias) }\end{array}$ & Low risk & $\begin{array}{l}\text { All patients referred were randomised into the study. As referrals were from } \\
\text { multiple sources it would not have been possible for allocations to be known } \\
\text { when patients were referred. }\end{array}$ \\
\hline
\end{tabular}

\begin{tabular}{|c|c|c|}
\hline $\begin{array}{l}\text { Blinding of participants } \\
\text { and personnel (perfor- } \\
\text { mance bias) } \\
\text { All outcomes }\end{array}$ & Low risk & Test products in identical jars. \\
\hline $\begin{array}{l}\text { Blinding of outcome as- } \\
\text { sessment (detection bias) } \\
\text { All outcomes }\end{array}$ & Low risk & Clearly stated - outcome assessment was blinded. \\
\hline $\begin{array}{l}\text { Incomplete outcome data } \\
\text { (attrition bias) } \\
\text { All outcomes }\end{array}$ & Low risk & $\begin{array}{l}\text { Outcome data was reported for all participants, using a combined score, in- } \\
\text { cluding erythema. }\end{array}$ \\
\hline
\end{tabular}

\begin{tabular}{lll}
\hline $\begin{array}{l}\text { Selective reporting (re- } \\
\text { porting bias) }\end{array}$ & Low risk & None apparent. \\
\hline Other bias & Unclear risk & None apparent. \\
\hline $\begin{array}{l}\text { Comparability of the two } \\
\text { arms }\end{array}$ & Low risk & $\begin{array}{l}\text { Activity scores were similar at baseline: '4.2 +/- 0.9' pimecrolimus vs '4.4 +/- } \\
2.6 \text { ' betamethasone }\end{array}$ \\
\hline
\end{tabular}

Jemec 2009

\begin{tabular}{ll}
\hline Methods & RCT, 8 weeks. \\
\hline Participants & 37 adults with DLE, clinically and histologically. \\
\hline Interventions & R-salbutamol 0.5\% topical cream vs placebo, applied twice daily. \\
\hline Outcomes & CLASI score; clinician global assessment; participant global assessment, adverse events ${ }^{\star}$. \\
\hline Notes & * Reported complete resolution, but not relapse rate or $50 \%$ clearing of erythema \\
\hline
\end{tabular}


Jemec 2009 (Continued)

Two authors receive support from Astion Pharma A/S.

\section{Risk of bias}

\begin{tabular}{|c|c|c|}
\hline Bias & Authors' judgement & Support for judgement \\
\hline $\begin{array}{l}\text { Random sequence genera- } \\
\text { tion (selection bias) }\end{array}$ & Low risk & $\mathrm{RCT}$, using random number chart. \\
\hline $\begin{array}{l}\text { Allocation concealment } \\
\text { (selection bias) }\end{array}$ & Unclear risk & $\begin{array}{l}\text { "The randomisation list consisted of randomisation numbers } 1-64 \text { and } \\
\text { uniquely assigned each patient to one of the two treatments". It was not clear } \\
\text { whether this list was kept hidden from investigators who were responsible for } \\
\text { recruitment. }\end{array}$ \\
\hline $\begin{array}{l}\text { Blinding of participants } \\
\text { and personnel (perfor- } \\
\text { mance bias) } \\
\text { All outcomes }\end{array}$ & Low risk & Assessors and participants were blinded; creams appeared identical. \\
\hline $\begin{array}{l}\text { Blinding of outcome as- } \\
\text { sessment (detection bias) } \\
\text { All outcomes }\end{array}$ & Low risk & Assessors and participants were blinded; creams appeared identical. \\
\hline $\begin{array}{l}\text { Incomplete outcome data } \\
\text { (attrition bias) } \\
\text { All outcomes }\end{array}$ & Low risk & $\begin{array}{l}\text { Intent-to-treat analysis was carried out on all patients randomised, with last } \\
\text { observation carried forward for any missing values. }\end{array}$ \\
\hline $\begin{array}{l}\text { Selective reporting (re- } \\
\text { porting bias) }\end{array}$ & High risk & Impact on erythema: no detail supplied. \\
\hline Other bias & Unclear risk & Short duration (6 weeks). \\
\hline $\begin{array}{l}\text { Comparability of the two } \\
\text { arms }\end{array}$ & Low risk & $\begin{array}{l}\text { At baseline, the groups were similar according to score. All participants had an } \\
\text { active lesion. }\end{array}$ \\
\hline
\end{tabular}

\section{Kuhn 2011}

\begin{tabular}{ll}
\hline Methods & Within-patient RCT, 12 weeks; diagnosis clinical and histological. \\
\hline Participants & 30 adults with cutaneous LE; 14 of them with DLE (subgroup analysis). \\
\hline Interventions & Tacrolimus 0.1\% cream vs placebo (vehicle). \\
\hline Outcomes & Digital photography; clinical score; participant satisfaction, adverse events* \\
\hline Notes & * Did not report complete resolution, relapse rate. \\
& Astellas Pharma Gmbll assisted with protocol design.
\end{tabular}

\section{Risk of bias}

\begin{tabular}{lll}
\hline Bias & Authors' judgement & Support for judgement \\
\hline $\begin{array}{l}\text { Random sequence genera- } \\
\text { tion (selection bias) }\end{array}$ & Low risk & Computer generated. \\
\hline
\end{tabular}


Kuhn 2011 (Continued)

$\begin{array}{ll}\begin{array}{l}\text { Allocation concealment } \quad \text { Low risk } \\ \text { (selection bias) }\end{array} & \begin{array}{l}\text { Allocation by pharmacy independent of the investigators. Quote "patients } \\ \text { were randomly assigned to either } 0.1 \% \text { tacrolimus ointment or the placebo } \\ \text { (vehicle) by the pharmacy at each center". }\end{array}\end{array}$

Blinding of participants Low risk $\quad$ Containers identical.
and personnel (perfor-
mance bias)
All outcomes

Blinding of outcome as- Low risk "Patients and physicians were blinded during the trial". sessment (detection bias)

All outcomes

\begin{tabular}{ll}
\hline $\begin{array}{l}\text { Incomplete outcome data } \\
\text { (attrition bias) }\end{array}$ & $\begin{array}{l}2 \text { of the } 14 \text { participants with DLE did not complete the trial. Intention to treat } \\
\text { analysis was used in a secondary analysis. }\end{array}$ \\
All outcomes &
\end{tabular}

\begin{tabular}{lll}
\hline $\begin{array}{l}\text { Selective reporting (re- } \\
\text { porting bias) }\end{array}$ & Unclear risk & Not apparent. \\
\hline Other bias & Unclear risk & None apparent. \\
\hline $\begin{array}{l}\text { Comparability of the two } \\
\text { arms }\end{array}$ & Low risk & Matched skin lesions used in individual participants. \\
\hline
\end{tabular}

\section{Roenigk 1980}

\begin{tabular}{ll}
\hline Methods & $\begin{array}{l}\text { RCT, cross-over at } 6 \text { weeks, duration } 12 \text { weeks. Data was analysed at } 6 \text { weeks as a parallel trial; data af- } \\
\text { ter the cross-over component was excluded. }\end{array}$ \\
\hline Participants & 78 adults, clinical diagnosis DLE well-matched. \\
\hline Interventions & Fluocinonide cream $0.05 \%$ vs hydrocortisone cream $1 \%$ given 3 times daily without occlusion. \\
\hline Outcomes & $\begin{array}{l}\text { Skin cleared or much improved - the lowest score of } 1 \text { if the lesion was worse, the highest score } 5 \text { if the } \\
\text { lesion was excellent or clear*. }\end{array}$ \\
\hline Notes & $\begin{array}{l}{ }^{*} \text { Did report resolution and adverse events, not } \% \text { change in erythema, relapse rate or participant satis- } \\
\text { faction. }\end{array}$
\end{tabular}

\section{Risk of bias}

\begin{tabular}{lll}
\hline Bias & Authors' judgement & Support for judgement \\
\hline $\begin{array}{l}\text { Random sequence genera- } \\
\text { tion (selection bias) }\end{array}$ & Low risk & $\begin{array}{l}\text { "Patients were randomly assigned... " "Statistical tests of equality ..showed } \\
\text { successful randomisation". }\end{array}$ \\
\hline $\begin{array}{l}\text { Allocation concealment } \\
\text { (selection bias) }\end{array}$ & Unclear risk & $\begin{array}{l}\text { No details about how the allocation sequence was concealed from the partici- } \\
\text { pants and clinicians. Creams were provided in identical base. }\end{array}$ \\
\hline $\begin{array}{l}\text { Blinding of participants } \\
\text { and personnel (perfor- } \\
\text { mance bias) } \\
\text { All outcomes }\end{array}$ & Low risk & Described as a "double-blind" trial. \\
& $\begin{array}{l}\text { "Both medications were supplied in a specifically formulated cream base...in } \\
\text { identical tubes". Participants had one active lesion which was monitored every } \\
3 \text { weeks - it is not clear if they were aware which lesion this was. }\end{array}$
\end{tabular}


Roenigk 1980 (Continued)

Blinding of outcome as- Unclear risk Not stated, but "double-blind". sessment (detection bias)

All outcomes

\begin{tabular}{lll}
$\begin{array}{l}\text { Incomplete outcome data } \\
\text { (attrition bias) } \\
\text { All outcomes }\end{array}$ & High risk & $\begin{array}{l}78 \text { of } 93 \text { participants were assessed at } 6 \text { weeks, } 15 \text { of the } 93 \text { patients who did } \\
\text { not complete the first phase of the study did so for reasons which may relate } \\
\text { to outcome. }\end{array}$ \\
\hline $\begin{array}{l}\text { Selective reporting (re- } \\
\text { porting bias) }\end{array}$ & Low risk & Not apparent. \\
\hline Other bias & Unclear risk & Short duration (6 weeks). \\
\hline $\begin{array}{l}\text { Comparability of the two } \\
\text { arms }\end{array}$ & Low risk & $\begin{array}{l}\text { The fluocinonide and hydrocortisone groups were similar at baseline with re- } \\
\text { spect to sex, age, race, duration of disease and duration of monitored lesion. }\end{array}$
\end{tabular}

Ruzicka 1992

\begin{tabular}{ll}
\hline Methods & RCT, duration 8 weeks (included DLE and subacute LE). \\
\hline Participants & 58 adults, clinical diagnosis DLE or SCLE, not matched for diagnosis. \\
\hline Interventions & Acitretin $50 \mathrm{mg}$ vs hydroxychloroquine $400 \mathrm{mg}$ daily. \\
\hline Outcomes & $\begin{array}{l}\text { An ordinal scale used to assess the skin initially and at follow-up visits: Complete clearing }=0, \text { improve- } \\
\text { ment }=1, \text { no change or deterioration }=2 . \text { Clearing of skin lesions and erythema were assessed }\end{array}$ \\
\hline
\end{tabular}

Notes

Reported complete resolution and adverse events, not participant satisfaction or relapse rate.

\section{Risk of bias}

\begin{tabular}{lll}
\hline Bias & Authors' judgement & Support for judgement \\
\hline $\begin{array}{l}\text { Random sequence genera- } \\
\text { tion (selection bias) }\end{array}$ & Low risk & $\begin{array}{l}\text { "..was conducted in a randomised fashion" and "patients were randomly as- } \\
\text { signed" but no further details }\end{array}$ \\
\hline $\begin{array}{l}\text { Allocation concealment } \\
\text { (selection bias) }\end{array}$ & Unclear risk & $\begin{array}{l}\text { No details about how the allocation sequence was concealed from the partici- } \\
\text { pants and clinicians. }\end{array}$ \\
\hline $\begin{array}{l}\text { Blinding of participants } \\
\text { and personnel (perfor- } \\
\text { mance bias) }\end{array}$ & Low risk & Study described as "double-blind" - but no further details were given. \\
$\begin{array}{l}\text { All outcomes } \\
\begin{array}{l}\text { Blinding of outcome as- } \\
\text { sessment (detection bias) }\end{array}\end{array}$ & Unclear risk & $\begin{array}{l}\text { Stated as double-blind but no details given as to how outcome assessors were } \\
\text { blinded. }\end{array}$ \\
\hline $\begin{array}{l}\text { Incomplete outcome data } \\
\text { (attrition bias) }\end{array}$ & Low risk & $\begin{array}{l}\text { 2 out of } 60 \text { patients randomised did not contribute to the analysis. ITT not de- } \\
\text { scribed. }\end{array}$ \\
\hline $\begin{array}{l}\text { Selective reporting (re- } \\
\text { porting bias) }\end{array}$ & Unclear risk & None apparent. \\
\hline
\end{tabular}


Ruzicka 1992 (Continued)

\begin{tabular}{lll} 
Other bias & High risk & Clinical heterogeneity. \\
\hline $\begin{array}{l}\text { Comparability of the two } \\
\text { arms }\end{array}$ & High risk & More participants with DLE in hydroxychloroquine group.
\end{tabular}

\section{Characteristics of excluded studies [ordered by study ID]}

\begin{tabular}{|c|c|}
\hline Study & Reason for exclusion \\
\hline Avgerinou 2012 & Results for DLE subset not reported; not an RCT. \\
\hline Bezerra 2005 & Trial results included other disorders, outcome in DLE could not be established. \\
\hline Bjornberg 1963 & Not randomised trial. \\
\hline Furie 2015a & Participants with SLE, results for DLE subset not reported. \\
\hline Furie 2015b & Participants with SLE, results for DLE subset not reported. \\
\hline Gammon 2011 & Not an RCT. \\
\hline Islam 2012 & Participants with SLE, results for DLE subset not reported. \\
\hline Khamashta 2016 & Participants with SLE, results for DLE subset not reported. \\
\hline Kraak 1965 & Not RCT. \\
\hline Kuhn 2011a & Photoprotection trial, not drug treatment. \\
\hline Kuhn 2016 & Not RCT. \\
\hline Madan 2010 & Not RCT. Results for DLE subset not reported separately. \\
\hline Manzi 2012 & Study of people with SLE. Results for DLE not reported. \\
\hline Merrill 2010a & Study of people with SLE. Results for DLE not reported. \\
\hline Merrill 2010b & Study of people with SLE. Results for DLE not reported \\
\hline Merrill 2011 & Study of people with SLE. Results for DLE not reported. \\
\hline Ordi-Ros 2000 & Not RCT. \\
\hline Szepietowski 2013 & Study of people with SLE. Results for DLE not reported. \\
\hline Thivolet 1990 & Not RCT. \\
\hline Tzung 2007 & $\begin{array}{l}\text { Most participants had malar rash of acute SLE (13 of 18). Results for DLE subset ( } 4 \text { people) could not } \\
\text { be established. }\end{array}$ \\
\hline Wang 2015 & Uncertain diagnosis. \\
\hline Yokogawa 2015 & Included participants with all forms of lupus, results for DLE subset not reported. \\
\hline
\end{tabular}




\begin{tabular}{ll}
\hline Study & Reason for exclusion \\
\hline Zhong 2013 & Participants with SLE, results for DLE subset not reported.
\end{tabular}

Characteristics of studies awaiting assessment [ordered by study ID]

NCT00001680

\begin{tabular}{ll}
\hline Methods & RCT, two matched lesions in same participant. \\
\hline Participants & 17 adults with DLE. \\
\hline Interventions & Thalidomide 20\% ointment under occlusion. \\
\hline Outcomes & Completed. \\
\hline Notes & - \\
\hline
\end{tabular}

\section{NCT00222183}

\begin{tabular}{ll}
\hline Methods & RCT. \\
\hline Participants & Peope with DLE, all ages. \\
\hline Interventions & Pimecrolimus cream vs betamethasone valerate $0.1 \%$ cream. \\
\hline Outcomes & Clinical score, adverse events. \\
\hline Notes & - \\
\hline
\end{tabular}

NCT00625157

\begin{tabular}{ll}
\hline Methods & Randomised, double-blind trial. \\
\hline Participants & Adults with DLE. \\
\hline Interventions & ASF cream 0.5\% (R-salbutamol) vs placebo. \\
\hline Outcomes & GA, CLASI, QoL. \\
\hline Notes & Completed, results not posted.
\end{tabular}

\section{NCT00625521}

\begin{tabular}{ll}
\hline Methods & RCT, multicentre. \\
\hline Participants & 32 adults with DLE. \\
\hline Interventions & ASF cream vs placebo.
\end{tabular}

Drugs for discoid lupus erythematosus (Review) 
NCT00625521 (Continued)

Outcomes Notes
Safety, CLASI, Global assessment by participant and investigator.

Completed 2007.

\section{NCT01164917}

\begin{tabular}{ll}
\hline Methods & RCT, cross-over study. \\
\hline Participants & 16 adults with DLE. \\
\hline Interventions & AMG811 (interferon gamma blocker) injection vs placebo. \\
\hline Outcomes & Safety; secondary outcome is CLASI score changes. \\
\hline Notes & Passed completion date. \\
\hline
\end{tabular}

\section{NCT01300208}

\begin{tabular}{ll}
\hline Methods & Randomised, double-blind study. \\
\hline Participants & People with DLE and SCLE. \\
\hline Interventions & CC 11050 (Celgene). \\
\hline Outcomes & Adverse effects, pharmacokinetics, CLASI. \\
\hline Notes & - \\
\hline
\end{tabular}

\section{NCT01407679}

\begin{tabular}{ll}
\hline Methods & Randomised, double-blind. \\
\hline Participants & 7 adults with cutaneous lupus. \\
\hline Interventions & Alitretinoin (Toctino ${ }^{\circledR}$ ) vs placebo. \\
\hline Outcomes & CLASI, percentage with improvement by global assessment, adverse events. \\
\hline Notes & - \\
\hline
\end{tabular}

\section{NCT01597050}

\section{Methods}

Participants

Interventions
Randomised, double-blind trial.

54 adults with DLE.

R932333 6\% cream vs placebo. 
NCT01597050 (Continued)

Outcomes Erythema and scaling score.

Notes Trial discontinued. Results not published.

Pothinamthong 2012

\begin{tabular}{ll}
\hline Methods & Randomised, to right or left side of the body, for 6 weeks. \\
\hline Participants & 21 Thai adults with DLE. \\
\hline Interventions & Tacrolimus $0.1 \%$ cream vs clobetasol propionate $0.05 \%$. \\
\hline Outcomes & CLASI score. \\
\hline Notes & Information from abstract only. We were unable to obtain full text.
\end{tabular}

\section{Characteristics of ongoing studies [ordered by study ID]}

\section{NCT02927457}

Trial name or title

A Double-blind (Sponsor Unblinded) Study to Investigate Safety, Tolerability, Pharmacokinetics, Pharmacodynamics and Clinical Effect of Repeat Dosing of GSK2646264 in Cutaneous Lupus Erythematosus Patients

\begin{tabular}{ll}
\hline Methods & Randomised, double-blind trial. \\
\hline Participants & 40 people with cutaneous LE. \\
\hline Interventions & GSK2646264 1\% cream vs placebo. \\
\hline Outcomes & Adverse effects, CLASI, pharmacokinetics. \\
\hline Starting date & January 2017. \\
\hline Contact information & US GSK Clinical Trials Call Center \\
& 877-379-3718 \\
GSKClinicalSupportHD@gsk.com
\end{tabular}

\section{Notes}

DATA AND ANALYSES 
Comparison 1. Fluocinonide versus hydrocortisone cream

\begin{tabular}{lllll}
\hline Outcome or subgroup title & No. of studies & $\begin{array}{l}\text { No. of partici- } \\
\text { pants }\end{array}$ & Statistical method & Effect size \\
\hline 1 Resolution of skin lesions & 1 & & Risk Ratio (M-H, Fixed, 95\% Cl) & Totals not selected \\
\hline
\end{tabular}

Analysis 1.1. Comparison 1 Fluocinonide versus hydrocortisone cream, Outcome 1 Resolution of skin lesions.

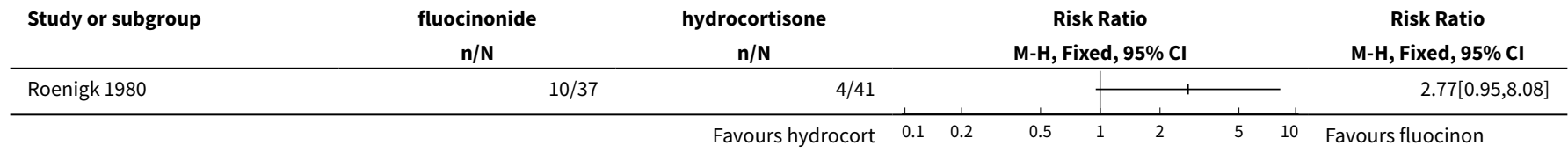

\section{Comparison 2. Acitretin versus hydroxychloroquine}

\begin{tabular}{lllll}
\hline Outcome or subgroup title & No. of studies & $\begin{array}{l}\text { No. of partici- } \\
\text { pants }\end{array}$ & Statistical method & Effect size \\
\hline 1 Resolution of skin lesions & 1 & Risk Ratio (M-H, Fixed, 95\% Cl) & Totals not selected \\
\hline 2 Clearing of erythema & 1 & Risk Ratio (M-H, Fixed, 95\% Cl) & Totals not selected \\
\hline
\end{tabular}

Analysis 2.1. Comparison 2 Acitretin versus hydroxychloroquine, Outcome 1 Resolution of skin lesions.

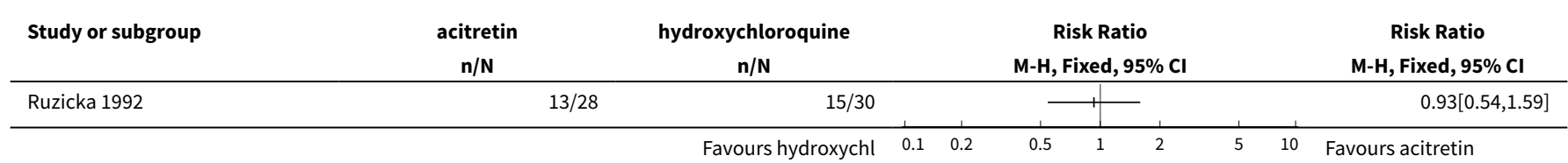

Analysis 2.2. Comparison 2 Acitretin versus hydroxychloroquine, Outcome 2 Clearing of erythema.

\begin{tabular}{|c|c|c|c|c|}
\hline Study or subgroup & $\begin{array}{l}\text { acitretin } \\
\mathrm{n} / \mathrm{N}\end{array}$ & $\begin{array}{c}\text { hydroxychloroquine } \\
n / N\end{array}$ & $\begin{array}{c}\text { Risk Ratio } \\
\text { M-H, Fixed, 95\% Cl }\end{array}$ & $\begin{array}{c}\text { Risk Ratio } \\
\text { M-H, Fixed, } 95 \% \mathrm{Cl} \\
\end{array}$ \\
\hline Ruzicka 1992 & $10 / 24$ & $17 / 25$ & + & $0.61[0.36,1.06]$ \\
\hline
\end{tabular}

\section{APPENDICES}

\section{Appendix 1. CENTRAL (Cochrane Library) search strategy}

$\# 1$ discoid lupus erythematosus

\#2 (cutaneous or skin) and lupus erythematosus

\#3 MeSH descriptor: [Lupus Erythematosus, Cutaneous] explode all trees 
\#4 MeSH descriptor: [Lupus Erythematosus, Discoid] explode all trees \#5 \#1 or \#2 or \#3 or \#4

\section{Appendix 2. MEDLINE (Ovid) search strategy}

1. discoid lupus erythematosus.mp.

2. Lupus Erythematosus, Cutaneous/

3. cutaneous lupus.mp.

4. Lupus Erythematosus, Discoid/

5. or/1-4

6. randomised controlled trial.pt.

7. controlled clinical trial.pt.

8. randomized.ab.

9. placebo.ab.

10. clinical trials as topic.sh.

11. randomly.ab.

12. trial.ti.

13. 6 or 7 or 8 or 9 or 10 or 11 or 12

14. exp animals/ not humans.sh.

15. 13 not 14

16. 5 and 15

[Lines 6-15: Cochrane Highly Sensitive Search Strategy for identifying randomised trials in MEDLINE: sensitivity-and precision-maximizing version (2008 revision)]

\section{Appendix 3. Embase (Ovid) search strategy}

1. discoid lupus erythematosus/

2. discoid lupus erythematosus.mp.

3. skin lupus erythematosus/

4. cutaneous lupus erythematosus.mp.

5. or/1-4

6. crossover procedure.sh.

7. double-blind procedure.sh.

8. single-blind procedure.sh.

9. (crossover\$ or cross over\$).tw.

10. placebo\$.tw.

11. (double $\$$ adj blind\$).tw.

12. allocat\$.tw.

13. trial.ti.

14. randomised controlled trial.sh.

15. random\$.tw.

16. or/6-15

17. exp animal/ or exp invertebrate/ or animal experiment/ or animal model/ or animal tissue/ or animal cell/ or nonhuman/

18. human/ or normal human/

19. 17 and 18

20. 17 not 19

21.16 not 20

22. 5 and 21

\section{Appendix 4. LILACS search strategy}

(discoid\$ and lupus and (erythematosus or eritematoso))

These terms combined with the Controlled clinical trials topic-specific query filter.

\section{WHAT'S NEW}

\begin{tabular}{lll}
\hline Date & Event & Description \\
\hline 22 September 2016 & New search has been performed & $\begin{array}{l}\text { We added three new studies and updated the review according } \\
\text { to MECIR. }\end{array}$ \\
\hline
\end{tabular}

Drugs for discoid lupus erythematosus (Review) 


\begin{tabular}{lll}
\hline Date & Event & Description \\
\hline 22 September 2016 & $\begin{array}{l}\text { New citation required but conclusions } \\
\text { have not changed }\end{array}$ & $\begin{array}{l}\text { The three new studies did not address any of the review's prima- } \\
\text { ry outcomes. }\end{array}$ \\
\hline
\end{tabular}

\section{HISTORY}

Protocol first published: Issue 3, 1999

Review first published: Issue 1, 2001

\begin{tabular}{lll}
\hline Date & Event & Description \\
\hline 6 August 2009 & $\begin{array}{l}\text { New citation required but conclusions } \\
\text { have not changed }\end{array}$ & Change to authors \\
\hline 11 June 2009 & New search has been performed & Further search carried out, no new studies found \\
\hline 28 November 2008 & Amended & New search completed, no studies found \\
\hline 1 November 2008 & Amended & Converted to new review format \\
\hline 2 January 2008 & Amended & New studies found and included or excluded \\
\hline 2 January 2008 & Amended & Conclusions changed \\
\hline 1 January 2008 & $\begin{array}{l}\text { New citation required and conclusions } \\
\text { have changed }\end{array}$ & Substantive amendment \\
\hline 3 September 2003 & Amended & New studies sought but none found \\
\hline
\end{tabular}

\section{CONTRIBUTIONS OF AUTHORS}

SJ was the contact person with the editorial base, SJ co-ordinated contributions from the co-authors, and wrote the final draft of the review, with DW.

SJ, DW, PJ screened papers against eligibility criteria.

SJ obtained data on ongoing and unpublished studies.

SJ, DW, PJ appraised the quality of papers.

SJ, DW extracted data for the review and sought additional information about papers.

SJ, MG, DW entered data into RevMan 5.

MG, DW, SJ analysed and interpreted data.

MG, SJ, DW worked on the methods sections.

SJ, DW drafted the clinical sections of the background and responded to the clinical comments of the referees.

$M G$ responded to the methodology and statistics comments of the referees.

\section{Disclaimer}

This project was supported by the National Institute for Health Research (NIHR), via Cochrane Infrastructure funding to the Cochrane Skin Group. The views and opinions expressed herein are those of the authors and do not necessarily reflect those of the Systematic Reviews Programme, NIHR, National Health Service or the Department of Health.

\section{DECLARATIONS OF INTEREST}

Sue Jessop: I receive a small annual amount from royalties relating to the sale of a book on Primary Care Dermatology, which is not related to the subject of the review.

David A Whitelaw: nothing to declare.

Matthew J Grainge: nothing to declare. 
Prativa Jayasekera: nothing to declare.

\section{SOURCES OF SUPPORT}

\section{Internal sources}

- Nottingham University, UK.

\section{External sources}

- The National Institute for Health Research (NIHR), UK.

The NIHR, UK, is the largest single funder of the Cochrane Skin Group.

\section{DIFFERENCES BETWEEN PROTOCOL AND REVIEW}

\section{Differences between the protocol and the current update}

For differences between other published versions, please see the 'Differences between protocol and review section' within the original publications.

Note: many of the methods section headings are missing from the protocol and previously published versions. In this update, we have tried to rectify this, in line with the current Cochrane Handbook and RevMan software.

Background: this section has been updated.

Objectives: the sentence 'To identify the need for further study to make rational clinical decisions possible when treating cutaneous lupus' was omitted from this update in line with current Cochrane Handbook for Systematic Reviews of Interventions and RevMan 5 software and the previously published versions of the review as it was considered redundant.

Types of interventions: we planned to include other anti-malarial quinines other than chloroquine and hydroxychloroquine, but did not find any RCTs for these interventions. Although not planned in the protocol, in this update we did additionally include lenalidomide, biological agents, (including abatacept, adalimumab, belimumab, etanercept, efalizumab, infliximab, rituximab, sifalimumab and sirukumab), topical calcineurin antagonists, (tacrolimus and pimecrolimus) and topical salbutamol as these agents had become available and trials had been performed in connective tissue disorders. We also clarified the types of comparators we would accept, as this detail was not specified in the protocol. We expanded the list of excluded interventions to include phototherapy and photoprotection, which were not originally listed in the protocol, for clarification only. This does not represent a change in methodology.

Types of outcome measures: in a previous version of the review, under Primary outcomes, we added 'percentage of people with' to our 'complete resolution of skin lesions...' and 'clearing of erythema...' outcomes, and these have been retained (Jessop 2009). Note that we accepted the following terms to describe complete resolution: complete clearing, clearing, marked improvement and excellent improvement.

Searching other resource: although not planned in the protocol, we searched Index Medicus by hand for studies relating to treatment of discoid lupus erythematosus for the years 1956 to 1966 because we thought it important, and we recorded all adverse events reported in the included and excluded studies as we recognise the need to report adverse events.

Search methods for identification of studies: the databases and date ranges that we planned to search in the protocol have been extended for this update review, in line with current standard search methods.

Data collection and analysis: In the original protocol, we had not made plans at all regarding how to deal with within-patient studies, missing data, sensitivity analysis, and 'Summary of findings' tables, but we now have in line with current requirements.

Where results are estimated for individual studies with low numbers of outcomes ( $<10$ in total) or where the total sample size is less than 30 participants, we decided to report the proportion of outcomes in each treatment group together with a P value from a Fisher's Exact test. This follows guidance provided by the Skin Group Statistics editors on how to deal with small numbers, made available since the last update of this review.

"We tested statistical heterogeneity using the $\mathrm{I}^{2}$ statistic (0\% to 40\%: may not be important; $30 \%$ to $60 \%$ : may represent moderate heterogeneity; 50\% to 90\%: may represent substantial heterogeneity; $75 \%$ to 100\%: represents considerable heterogeneity) (Higgins 2011)." An assessment of how we would deal with heterogeneity was missing from the original protocol therefore we have amended this at this stage in the event that future updates of this review will contain a pooled analysis of two or more studies.

Assessment of risk of bias in included studies: the text within this section was written in the 'Quality rating of included studies' section of the protocol. The review has been amended to follow the RevMan 5 recommended headings and the new Cochrane Handbook for Systematic Reviews of Interventions guidelines. 
Two additional headings have been added to this section: Comparability of the two arms and Intention to treat analysis.

According to the Cochrane Handbook for Systematic Reviews of Interventions, controlled trials that allocate participants by quasirandomisation, or that fail to conceal allocation during recruitment, are at risk of selection bias. We have included such trials, but have indicated that there is high risk of selection bias.

Imbalance at baseline has been assessed in this version of the review and added to the risk of bias tables.

Measures of treatment effect: although not planned in the protocol, for any significant outcomes $(P<0.05)$ we wanted to present the number needed to treat for an additional harmful outcome (NNTH) where the first treatment in the comparison is harmful (risk ratio (RR) $>1$ for safety outcomes). We did not do this as no significant harms were reported.

In the protocol, we did not pre-state the effect measures that we would report. For dichotomous outcomes (primary outcomes 1 and 2 and adverse events), results are presented as RR with 95\% confidence intervals (Cl). For this update, for continuous outcomes (primary outcome 3), we planned to present results in the form of mean differences (with $95 \% \mathrm{Cls}$ ). Where there were treatment comparisons where studies used different scales for the same outcome, we planned to convert results to standard mean differences (SMD) to allow pooling of results. We could not carry out these plans because the studies were few and heterogeneous.

Unit of analysis issues > Cross-over trials: in the protocol we did not plan how to analyse cross-over trials; but having included such a study, we followed the guidance provided in Section 16.4.4 of the Cochrane Handbook for Systematic Reviews of Interventions (Higgins 2011). Where no evidence of a carry-over effect was present, analyses of paired differences were presented if these data could be obtained from the trial report. Otherwise, only data from the first treatment period were used.

Unit of analysis issues > Within-patient studies: although not planned in the protocol, internally controlled trials were analysed using techniques for paired designs (e.g. paired t-test, McNemar's test). Where appropriate, these were included in additional data tables and not pooled with parallel group trials.

Assessment of heterogeneity: in the protocol, we had planned to use statistical tests for homogeneity between studies. However, assessment of heterogeneity was not performed as no findings were based on pooled results from 2 or more trials.

Data synthesis: in the protocol, we planned to draw up a synthesis of included trials; however, this was not possible with the data in the studies we found, due to heterogeneity of study methods and interventions. No two trials investigated the same interventions.

Subgroup analysis and investigation of heterogeneity: in the protocol, we had planned to perform subgroup analysis on the following measures: disseminated DLE versus localised DLE; DLE with systemic lupus versus DLE without systemic lupus; histologically proven versus clinically diagnosed DLE; and effect of ethnic group on outcome. However, we were unable to address these issues, as none of the studies provided data on individual subgroups, (and two of the trials enrolled small numbers of participants).

Trials that included more than one subset of cutaneous lupus were included if most participants had DLE and the outcome data described outcomes for DLE.

Other: we planned where possible to calculate cost effectiveness ratios using quality-of life-measures; however, the studies identified did not provide these data.

'Summary of findings' table: although not planned in the protocol, we used GRADEpro 2008 to create a 'Summary of findings' table as suggested in the Cochrane Handbook for Systematic Reviews of Interventions (Higgins 2011). In this, we have summarised the primary outcomes for the most important comparisons. Subgroup analysis was not possible.

\section{INDEX TERMS}

\section{Medical Subject Headings (MeSH)}

Acitretin [adverse effects] [therapeutic use]; Albuterol [therapeutic use]; Calcineurin Inhibitors [therapeutic use]; Dermatologic Agents [adverse effects] [*therapeutic use]; Fluocinonide [therapeutic use]; Hydrocortisone [therapeutic use]; Hydroxychloroquine [therapeutic use]; Lupus Erythematosus, Discoid [ ${ }^{*}$ drug therapy]; Randomized Controlled Trials as Topic; Tacrolimus [analogs \& derivatives] [therapeutic use]; Treatment Outcome

\section{MeSH check words}

Humans 